\title{
Potential climate change impacts on water resources in the Auckland Region (N ew Zealand)
}

\author{
Anthony Fowler* \\ Department of G eography, University of A uckland, Private Bag 92019, A uckland, N ew Zealand
}

\begin{abstract}
Potential climate change impacts on water resources in the Auckland region (New Zealand) are assessed using scenarios of future climate change $(2020,2050,2100)$ and a daily water balance model to transform the scenarios into seasonal impacts on the soil water regime and catchment water yield. The climate change scenarios are derived in the form of best guesses and envelopes, the latter incorporating known quantifiable sources of uncertainty at the global and regional scales. The water balance model is driven by historical time series of precipitation and potential evaporation from 2 sites selected to represent regional differences in climate regime. Simulations for a range of site characteristics (vegetation, soil water storage capacity, soil drainage characteristics) are undertaken by making appropriate adjustments to model parameters. Impact assessments are nested within more general sensitivity analyses (response surfaces) of seasonal summary variables, derived from multiple runs of the water balance model with systematic changes to the input variables. Potential impacts are assessed by superimposing the climate scenarios onto the seasonal response surfaces and from frequency analysis across the range of plausible impacts. The scenario overlays give potential impacts on mean conditions, whereas the frequency analyses focus on changes at the $5 \mathrm{yr}$ return period level, important for water resource planning. A key result from the soil water regime analysis is that the direction of impacts is uncertain, for all scenarios, seasons, climate regimes, and site characteristics. The best guess is for negligible change. Intra-regional climate regime differences are important and vegetation cover significantly affects sensitivity. In contrast, water yield results indicate an unambiguous change to increased yield, especially over winter, although with very large uncertainties concerning the magnitude of the change. Differences in climate regime and site characteristics are again important. From a water resource perspective the study results show no cause for alarm. Within the context and limitations of the regional climate change scenarios used, detrimental impacts appear rather less likely than potential benefits, the latter possibly being substantial.
\end{abstract}

KEY WORDS: Climate change $\cdot$ Climate change impacts $\cdot$ Water resources

\section{INTRODUCTION}

Research into the potential impacts of future climate change associated with the greenhouse effect on water resources dates from the period of heightened modern concern in the early 1980s (e.g. Nemec \& Schaake 1982). M oreover, the issue has been clearly in front of most water resource planners at least since 1986, following wide circulation of the statement emerging from the UNEP/WMO/ICSU conference held at Villach, A ustria, in October 1985. This statement specifically identified water resources as an area where sen-

\footnotetext{
*E-mail: a.fowler@auckland.ac.nz
}

sitivity and impact assessment research should be strongly supported.

Research over the ensuing 2 decades has been characterised by a gradual increase in global coverage of impact assessments and evolution of the methodology. Concurrently, there has been increased focus on inherent uncertainties and increasingly explicit acknowledgment of significant limitations. Lins et al. (1991) acknowledge that statements of impacts are not possible due to an inability to forecast future conditions (climatic and socioeconomic), identifying sensitivity analyses as a suitable approach, given the uncertainties. Their conclusions, drawn from a review of sensitivity analyses up to the early 1990s, include recognition of the dominating importance of changes in 


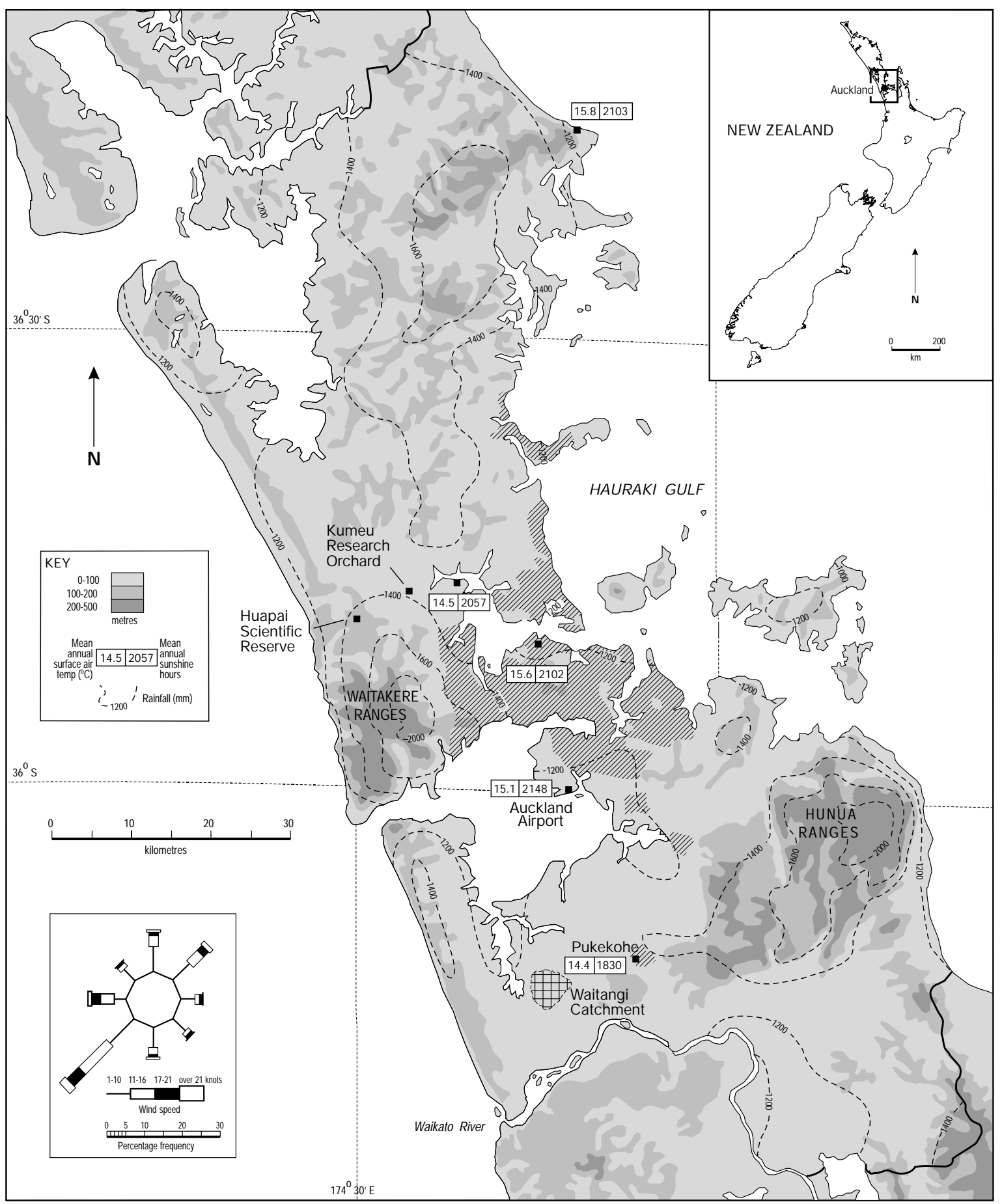

Fig. 1. The Auckland region, showing generalised topography, major urban areas (hatched), selected components of regional hydroclimatology, and locations referred to in the text

precipitation and the fact that relatively small changes in climate may have amplified water resource impacts - especially in arid and semi-arid environments and where water resources are in high demand.

Water resource impact studies through to the mid1990s are reviewed by Arnell et al. (1996). A feature of the review is the emphasis placed on uncertainties, ranging from regional climate projections, through downscaling to the local scale, to transformation into hydrological responses (accounting for possible changes in landcover and crop water use efficiency associated with higher concentration of atmospheric 
$\mathrm{CO}_{2}$ ). Partly due to these uncertainties, the conclusions drawn from a review of 19 recent case studies are limited, although high sensitivity of runoff to climate change, especially under drier conditions, is confirmed. Some regional patterns are identified, but limited by inadequate spatial coverage. For example, only 2 of the cases studies are from the Southern Hemisphere and both of those are Australian examples.

The impetus for the research detailed here arose from joint consideration of international developments and the concurrent nature of water resource use in the Auckland region, New Zealand (Fig. 1). With the urban water supply system operating close to design capacity and expectations that water available for irrigation would be fully allocated by the end of the century over much of the region, water resource use in the region is potentially vulnerable to climate change. Accordingly, the present study was initiated to assess the sensitivity of selected water resources in the Auckland region to climate variation and the potential impacts of future
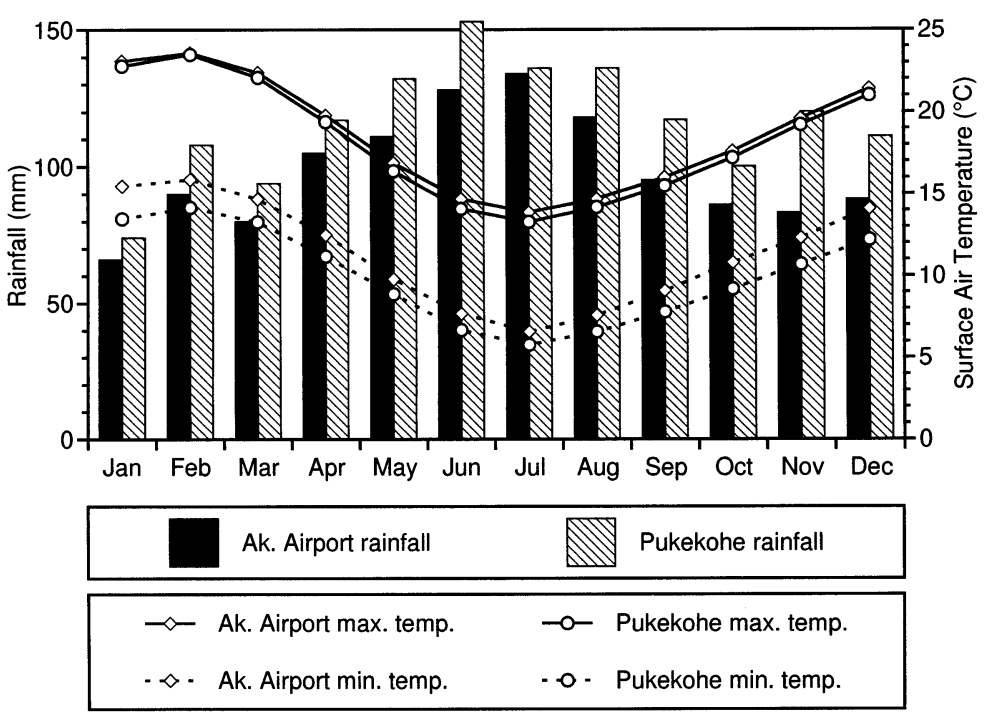

Fig. 2. Surface air temperature and rainfall normals for Auckland Airport and Pukekohe (1951 to 1980). Auckland Airport (15.1 ${ }^{\circ} \mathrm{C}$ mean surface air temperature, $1184 \mathrm{~mm}$ mean annual rainfall) is one of the warmest and driest sites in the region. Excluding the ranges, Pukekohe is one of the coolest and wettest sites, about $1.0^{\circ} \mathrm{C}$ cooler and $18 \%$ wetter than Auckland Airport. Data source: NZMS (1983b,c)

climate change associated with projected global warming. Results presented here relate to agricultural water resources, specifically the soil water regime and catchment water yield, over about the next $100 \mathrm{yr}$. The work adds a further Southern Hemisphere case study to the literature and does so in a manner strongly orientated towards accommodating uncertainties.

\section{REGIONAL HYDROCLIMATOLOGY}

Auckland's climate is primarily a function of its location and regional topography. Broad-scale features of the atmospheric circulation (subtropical high-pressure belt and higher latitude westerlies) dominate, with the latitudinal migration of these zonal circulation features responsible for most of the observed seasonal climate patterns. The influence of the westerlies is predominant, but with some significant subtropical influences, especially in summer when the westerlies tend to be centred to the south of New Zealand and the subtropical high-pressure belt moves south over the North Island. The weather pattern is dominated by an irregular succession of eastwardly migrating anticyclones and troughs, typically centred between $33^{\circ}$ and $40^{\circ} \mathrm{S}$ and with an interval of 3 to $7 \mathrm{~d}$ (Coulter 1975). The extensive ocean expanses over which air masses travel, the relatively subdued relief of the region, and the heavily indented peninsular coastline (Fig. 1) combine to produce a temperate-maritime climate (Fig. 2) with narrow diurnal and seasonal ranges of temperature and humidity. Characteristics of the regional climate relevant to water resources are summarised in Table 1.

From a hydrological perspective, regional variations in precipitation and potential evaporation (PE) tend to be mutually reinforcing. Because lower precipitation is typically associated with increased PE, variation in hydrological conditions tends to be amplified. Comparison of monthly water balance plots for Auckland Airport and Pukekohe (Fig. 3) indicates the scale of regional variation. Of the order of $50 \%$ of soil water is typically depleted by the end of the calendar year in relatively dry, sunny and warm parts of the region (e.g. Auckland Airport), with relatively large evaporation deficits (PE minus AE in Fig. 3) typically developing during mid- to late summer (J anuary-February). In contrast, evaporation deficits for the wetter and cooler Pukekohe site are smaller and occur over a shorter period, with a correspondingly more rapid soil water recharge. Combined with higher precipitation this leads to more rapid recovery of summer low flows and increased runoff in the southern part of the region.

Clearly, regional differences in hydroclimatology are not insignificant. In view of the importance of the climate regime in terms of assessing potential climate change impacts on water resources (de Freitas \& Fowler 1989), these regional differences need to be accommodated in any climate change impact assessment. 
Table 1. Selected elements of the climate of the Auckland region relevant to water resources. Sources: De Lisle (1965), Hurnard (1980), NZMS (1983a, 1986), Reid \& Penney (1982), Hessell (1988)

\begin{tabular}{|c|c|}
\hline Climate element & Characteristics \\
\hline Precipitation & $\begin{array}{l}\text { Effectively all rainfall } \\
\text { M ean annual rainfall varies over region from less than } 1200 \text { to ca } 2200 \mathrm{~mm} \\
\text { Higher rainfall primarily due to orographic effects (esp. Waitakere and Hunua Ranges) }\end{array}$ \\
\hline $\begin{array}{l}\text { Sunshine and } \\
\text { radiation }\end{array}$ & $\begin{array}{l}\text { M ean annual bright sunshine ranges from } 18: 30 \text { to } 21: 50 \mathrm{~h} \\
\text { M aximum radiation received over the central isthmus and NE coastline } \\
\text { M inimum values recorded in the SW } \\
\text { Regional variations due to morning fog in the SW and to higher cloudiness in western areas generally }\end{array}$ \\
\hline Wind & $\begin{array}{l}\text { SW dominant followed by } \mathrm{W} \text { then } \mathrm{NE} \\
\text { Light winds or calms experienced } 12 \text { to } 15 \% \text { of time in coastal areas and up to } 30 \% \text { in sheltered inland areas } \\
\text { Significant regional variation depending on exposure but gales rare }\end{array}$ \\
\hline Humidity & $\begin{array}{l}\text { M onthly mean vapour pressure ranges from } 10.7 \mathrm{hPa}(\mathrm{Jul}) \text { to } 17.7 \text { (Feb) } \\
\text { M onthly mean daily relative humidity ranges from } 74 \text { (Dec to Feb) to } 80 \% \text { (J un to Aug) }\end{array}$ \\
\hline $\begin{array}{l}\text { Surface air } \\
\text { temperature }\end{array}$ & $\begin{array}{l}\text { M onthly mean diurnal range of surface air temperature rarely exceeds } 10^{\circ} \mathrm{C} \\
\text { Summer daily maximum surface air temperatures in the mid-twenties typical } \\
\text { Temperatures over } 30^{\circ} \mathrm{C} \text { rare } \\
\text { Regional mean temperature differences small (primarily due to altitude) }\end{array}$ \\
\hline $\begin{array}{l}\text { Potential } \\
\text { evaporation (PE) }\end{array}$ & $\begin{array}{l}\text { Highest PE (ca } 1100 \mathrm{~mm} \mathrm{yr}^{-1} \text { ) on the sunnier, warmer east coast and isthmus } \\
\text { Ca } 20 \% \text { lower in some western and southern locations (ca } 900 \mathrm{~mm} \mathrm{yr}^{-1} \text { ) } \\
\text { Summer PE about twice summer mean rainfall }\end{array}$ \\
\hline
\end{tabular}
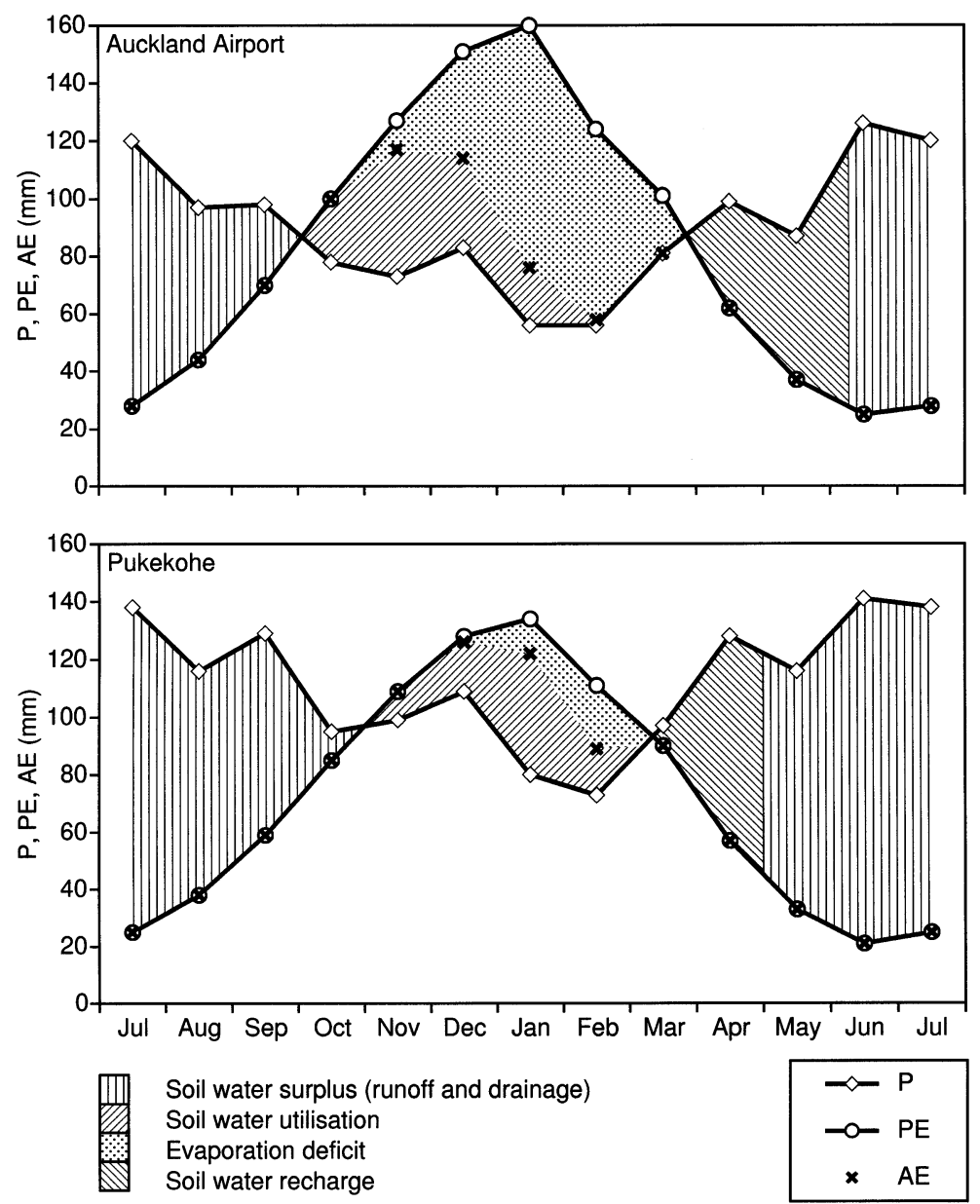

\section{RESEARCH FRAMEWORK}

Kates (1985) presents a series of conceptual models representing methodologies commonly adopted in climate change impact studies. Developing these ideas in the water context, Fowler (1992) derived the generic interaction model shown in Fig. 4, which indicates that the most important impact pathways are via biophysical systems and processes. The resulting biophysical impacts are what normally affect society, either in the form of hazards (e.g. floods) or by changing climate-related resources utilised by society (e.g. water resources). Several biophysical systems may be affected by climate variation and the impacts upon them are likely to be multiple, interrelated, and cascading. Inclusion of 'societal variation' in the conceptual model recognises the importance of society-specific factors (e.g. land use, level of technology, planning procedures, nature of resource utilisation) in

Fig. 3. Mean water budgets for Auckland Airport and Pukekohe. Calculated using mean monthly precipitation $(\mathrm{P})$ and potential evaporation (PE) given in NZMS (1986). Actual evaporation (AE) calculated after M ather (1974) 
Fig. 4. Schematic of a generic interaction model for climate change impacts, showing impact paths (solid lines) and possible feedbacks (dashed lines). Source: Fowler (1992)

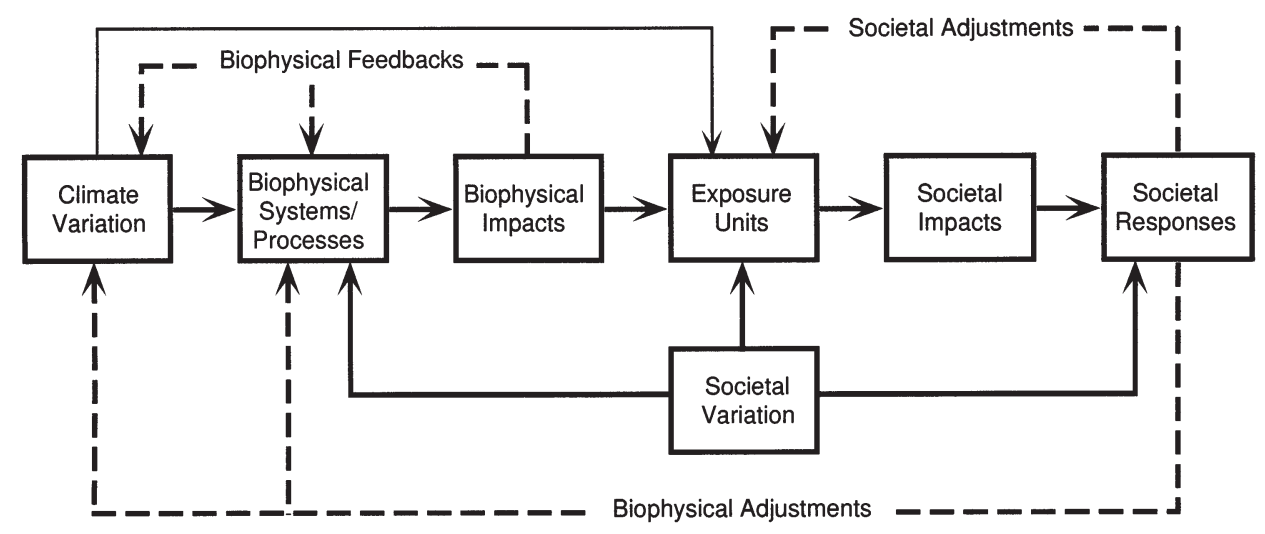

determining the nature of biophysical impacts, the sensitivity of 'exposure units' (e.g. a region or activity) to those impacts, and the response of society to actual or anticipated societal impacts. Note also that the impact pathway shown in Fig. 4 is not unidirectional. There is potential for feedback effects of either a biophysical or societal nature, due to the interdependence of biophysical systems, and because societal responses aimed at impact avoidance or mitigation may involve feedback effects on the impact pathway at a point preceding 'societal impacts'.

Climate change impact assessment requires translation of the generic interaction model presented in Fig. 4 into a research methodology appropriate for the exposure unit or units under consideration. For a specific society at a particular stage of development, the interaction model from 'climate variation' through to 'societal impacts' can often be reduced to an impact cascade through 3 sub-system levels. The first level is the global climate system; the second incorporates the various biophysical systems affected by climate variation (some themselves integral components of the climate system); the third incorporates societal systems that either exploit biophysical resources or are affected by biophysical hazards. For those exposure units where direct climate effects are negligible, and where evolving societal factors such as efficiency of resource use are not expected to be significant over the time scale of concern, 4 distinct research phases can be identified: (1) projection of future climate; (2) transformation of projections of future climate into biophysical impacts; (3) transformation of biophysical impacts into societal impacts; (4) identification of plausible societal responses.

Fig. 5 shows how the 4 research phases identified above are incorporated into a research framework appropriate for the present study. Projections of future climate are accommodated by deriving regional climate change scenarios, modified to allow for possible effects of a carbon-enriched atmosphere on plant water use. Impacts on the soil water regime and catch- ment water yield are derived using a mathematical model of the land phase of the hydrological cycle as the biophysical transfer function used to transform the climate change scenarios into potential impacts. A modified version of the same model serves as the exposure unit transfer function, used to assess implications for water supply and irrigation potential and cost. Finally, societal responses are identified in terms of plausible response scenarios, taking into account possible biophysical and societal adjustments. Note that only biophysical impacts are reported in this paper. The expanded research framework shown in Fig. 5 is presented for purposes of context and because application of the biophysical impact results influences the way those impacts need to be assessed (e.g. the form the hydrological model needs to take).

Biophysical feedbacks are a significant component of the interaction model presented as Fig. 4 but are not included in Fig. 5. This is because the environmental characteristics of the Auckland region and the research time frame combine to produce a situation where feedbacks are unlikely to be important (other than those related to response options). Only biophysical feedbacks associated with vegetation change have the potential to significantly affect water resource impacts. However, neither of the 2 dominant vegetation types (pasture, native forest) is near its climatic tolerance limits and the boundaries of each are anthropogenically determined. Significant hydrological feedbacks are therefore unlikely over the time frame being considered.

The usual approach to transforming projections of future climate into biophysical impacts is to calibrate an existing hydrological model at a specific site. Multiple model runs are then made with various adjustments to the climate input variables, designed to represent possible changes in climate. Assuming that the model is appropriate, assessing potential climate change impacts is a relatively simple process of comparing the output from the various model runs. In contrast, the approach taken here is to develop a hydro- 
a

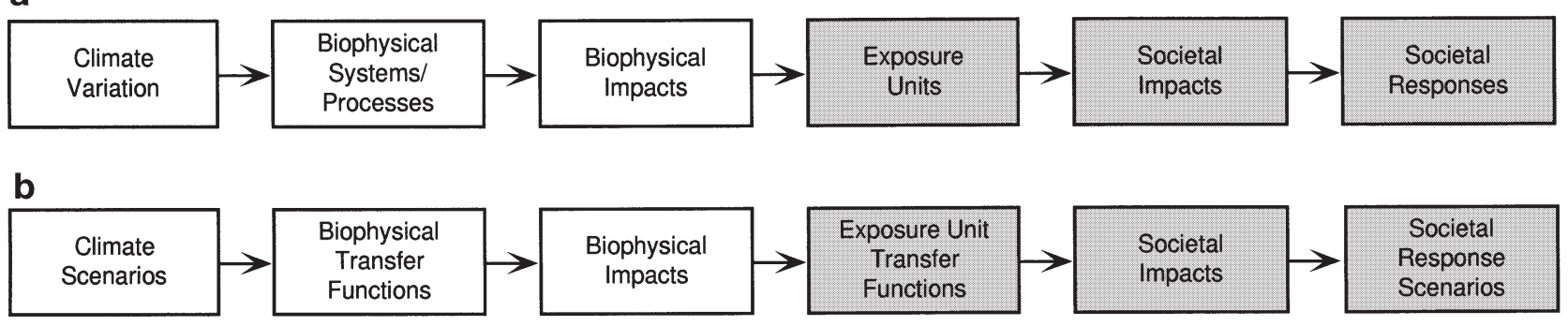

C

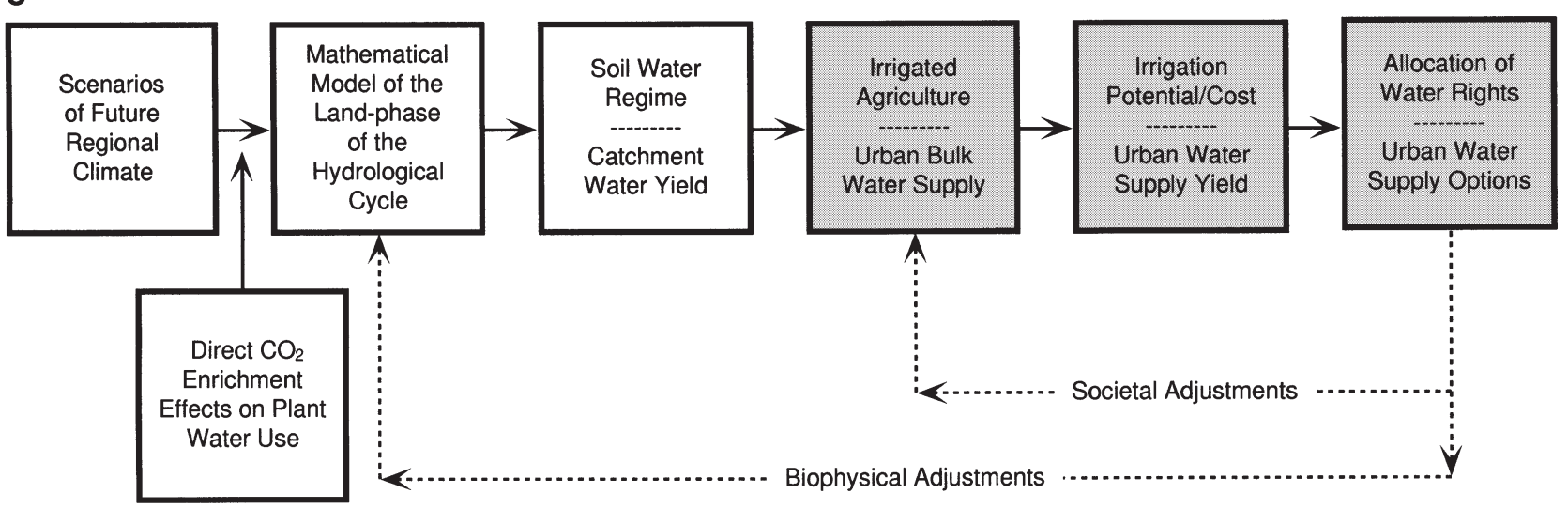

Fig. 5. Research framework schematic showing: (a) generic interaction model terminology from Fig. 4; (b) basic methodological terminology; (c) the specific elements comprising this research or which need to be considered in the derivation of the biophysical transfer function. Shaded boxes denote components of the research not reported in detail here

logical model which is simple and robust enough to be applicable under a range of hydrologically simple, homogenous environments. Although the model is developed and tested on specific sites, to ensure its suitability to the task, application in the climate change context is for hypothetical sites. This enables wide-ranging exploration of the sensitivity of simulated impacts to specific environmental circumstances. For example, by driving exactly the same model setup with input data from different locations, the sensitivity of the impact results to the climate regime can be isolated. A hypothetical site might represent a free-draining agricultural soil with a specific set of infiltration, drainage and soil water storage characteristics. The model parameters defining the relevant stores and fluxes can then be adjusted to examine how impacts might be expected to vary as these characteristics change.

\section{REGIONAL CLIMATE CHANGE SCENARIOS}

Following Fowler (1993), global and regional source material are combined here to produce regional climate change scenarios which reflect important sources of uncertainty about future climate change: sensitivity of global surface air temperature to increased atmospheric trace gases, future trace-gas emissions, regional climate responses to global warming, and the effect of higher levels of atmospheric $\mathrm{CO}_{2}$ on plant water use. The scenarios are founded on the IPCC global assessment of future climate change (Houghton et al. 1990, 1992, 1996). Specifically, the IPCC assessment of sensitivity of global mean surface air temperature to an effective doubling of $\mathrm{CO}_{2}\left(\Delta \mathrm{T}_{2 \times}\right)$ and the revised IPCC emissions scenarios (Leggett et al. 1992) are adopted. Actual projections of future global warming for 2020, 2050 and 2100 follow the methodology of Wigley \& Raper (1992) which also factors in changes in radiative forcing due to sulphate aerosols, stratospheric ozone depletion, and $\mathrm{CO}_{2}$ fertilisation. Results for 3 specific scenario dates considered here $(2020,2050,2100)$ are summarised in Table 2.

Details of regional temperature and precipitation changes (Table 3 ) are derived from published scenario development work (RSNZ 1988, Mullan \& Renwick 1990) and from the results of 3 GCM enhanced-greenhouse experiments post-dating that work, results for the latter extracted from contoured data-fiel ds over the New Zealand region, rather than individual grid points. Results for each scenario source are standardised in terms of changes in surface air temperature $\left({ }^{\circ} \mathrm{C}\right)$ 
Table 2. Low, best-guess, and high projections of the increase in global mean surface air temperature for 2020, 2050, and 2100. Derived using MAGICC (T.M.L. Wigley unpubl.), run with default settings for parameters other than those shown

\begin{tabular}{|c|c|c|c|c|c|}
\hline \multirow{2}{*}{$\begin{array}{l}\text { Global } \\
\text { warming } \\
\text { scenario }\end{array}$} & \multirow[t]{2}{*}{$\begin{array}{l}\text { Emissions } \\
\text { scenario }\end{array}$} & \multirow{2}{*}{$\begin{array}{r}\Delta \mathrm{T}_{2 \times} \\
\left({ }^{\circ} \mathrm{C}\right)\end{array}$} & \multicolumn{3}{|c|}{$\begin{array}{l}\text { Projected global } \\
\text { warming }\left({ }^{\circ} \mathrm{C}\right) \text { for: }\end{array}$} \\
\hline & & & 2020 & 2050 & 2100 \\
\hline Low & IS92C & 1.5 & 0.3 & 0.7 & 1.1 \\
\hline Best guess & IS92a & 2.5 & 0.5 & 1.2 & 2.5 \\
\hline High & IS92e & 4.5 & 0.9 & 2.1 & 4.5 \\
\hline
\end{tabular}

and precipitation (\%) per degree of global warming $\left(\Delta \mathrm{T}_{\mathrm{r} / \mathrm{g}}, \Delta \mathrm{P}_{\mathrm{r} / \mathrm{g}}\right)$, following the method of Santer et al. (1989).

N ote that the envelope approach to scenario development adopted here requires a lowest common denominator approach, in terms of the temporal scale used. This results in a potential loss of information in the case of the GCM sources where seasonal or even monthly differentiation is possible. This limitation is accepted and considered a relatively small sacrifice given the scale of differences in regional climates simulated by different GCMs or different generations of the same GCM , especially in the case of precipitation (see for example Chiew et al. 1995 and Boorman \& Sefton 1997).

Combining the global warming scenarios (Table 2) with the regional source data expressed in terms of change per degree of global warming (Table 3: $\Delta \mathrm{T}_{\mathrm{r} / \mathrm{g}}$, $\left.\Delta \mathrm{P}_{\mathrm{r} / \mathrm{g}}\right)$, gives low, best-guess, and high projections of change in surface air temperature $\left({ }^{\circ} \mathrm{C}\right)$ and precipitation (\%) for 2020, 2050, and 2100 for each of the 6 sources used (Fig. 6). Each panel in Fig. 6 shows results for temperature change for these dates, plotted against the corresponding precipitation change results. Straight lines connect low, best-guess, and high esti- mates for each regional source. Shading in each panel represents the scenario envelope, encompassing the combined uncertainties associated with climate sensitivity, future emissions, and regional response to global warming. Heavy crosses are best-guess estimates, based on the IPCC best guess of $2.5^{\circ} \mathrm{C}$ for $\Delta \mathrm{T}_{2 \times}$, the mid-range emissions scenario IS92a, and the scatter of regional results. All changes are on an annual basis and are expressed relative to 1990 .

Results shown in Fig. 6 indicate that the Auckland region may be 0.1 to $0.7^{\circ} \mathrm{C}$ warmer by 2020 , with an associated 0 to $4 \%$ increase in precipitation. By 2050, warming is expected to be 0.3 to $1.6^{\circ} \mathrm{C}$, with precipitation up to $9 \%$ greater. Further amplification by 2100 (assuming no significant international action to limit trace-gas emissions) is expected to result in temperature increases of 0.4 to $3.6^{\circ} \mathrm{C}$ and up to a $20 \%$ increase in precipitation. Based on the IPCC best guess of $2.5^{\circ} \mathrm{C}$ for $\Delta \mathrm{T}_{2 \times}$, the mid-range emissions scenario IS92a, and the scatter of regional results, best-guess estimates of regional temperature and precipitation increases are $0.4^{\circ} \mathrm{C}$ and $1.2 \%(2020), 0.8^{\circ} \mathrm{C}$ and $2.7 \%$ (2050), and $1.8^{\circ} \mathrm{C}$ and $5.8 \%$ (2100).

Scenario development to this point has been limited to changes to surface air temperature and precipitation, the only variables consistently available for analysis. Changes in PE, required for water resource applications, are based on a review of secondary sources which address the empirical relationship between surface air temperature and PE (Budyko 1980, cited in Nemec \& Schaake 1982, Shuttleworth 1983) or which examine the issue analytically through the PenmanMontieth equation (M artin et al. 1989, Rosenberg et al. 1989). This review, combined with the maritime character of Auckland's climate, and the fact that lighter winds and less sunshine are expected (Salinger \& Hicks 1990), leads to the adoption of a 2 to $4 \%$ increase

Table 3. Projections of future warming in the Auckland region, relative to $1990 . \Delta T_{r}$ and $\Delta P_{r}$ : regional projected changes in temperature $\left({ }^{\circ} \mathrm{C}\right)$ and precipitation (\%) for the 6 sources named. $\Delta \mathrm{T}_{\mathrm{g}}$ : the corresponding global temperature change $\left({ }^{\circ} \mathrm{C}\right)$ for each source. $\Delta \mathrm{T}_{\mathrm{r} / \mathrm{g}}$ and $\Delta \mathrm{P}_{\mathrm{r} / \mathrm{g}}$ : regional changes in temperature $\left({ }^{\circ} \mathrm{C}\right)$ and precipitation (\%) per degree of global warming. RSNZ (1988) results are for 2050. The Mullan \& Renwick (1990) results and results for the 3 GCM s (CCC, CSIRO9, GFDLH) are for an effective doubling of $\mathrm{CO}_{2}$. CCC: Canadian Climate Centre GCM; CSIRO9: Australian Commonwealth Scientific and Industrial Research Organization 9-layer GCM; GFDLH: United States Geophysical Fluid Dynamics Laboratory high resolution GCM. Details of CCC and GFDLH are given in Houghton et al. (1990). CSIRO9 is described in Gordon et al. (1992)

\begin{tabular}{|lccccc|}
\hline Source & $\Delta \mathrm{T}_{\mathrm{r}}\left({ }^{\circ} \mathrm{C}\right)$ & $\Delta \mathrm{P}_{\mathrm{r}}(\%)$ & $\Delta \mathrm{T}_{\mathrm{g}}\left({ }^{\circ} \mathrm{C}\right)$ & $\begin{array}{c}\Delta \mathrm{T}_{\mathrm{r} / \mathrm{g}} \\
\left({ }^{\circ} \mathrm{C} \text { per degree }\right. \\
\text { global warming) }\end{array}$ & $\begin{array}{c}\Delta \mathrm{P}_{\mathrm{r} / \mathrm{g}} \\
\text { (\% per degree } \\
\text { global warming) }\end{array}$ \\
\hline RSNZ (1988)-scenario 1 & +1.2 & +10 & +2.5 & +0.48 & +4.0 \\
RSNZ (1988)-scenario 2 & +3.5 & +10 & +4.5 & +0.78 & +2.2 \\
Mullan \& Renwick (1990) & +3.0 & +20 & +4.0 & +0.75 & +5.0 \\
CCC GCM & +3.1 & +10 & +3.5 & +0.89 & +2.9 \\
CSIRO9 GCM & +4.0 & +10 & +4.8 & +0.83 & +2.1 \\
GFDLH GCM & +3.5 & +5 & +4.0 & +0.88 & +1.3 \\
\hline
\end{tabular}



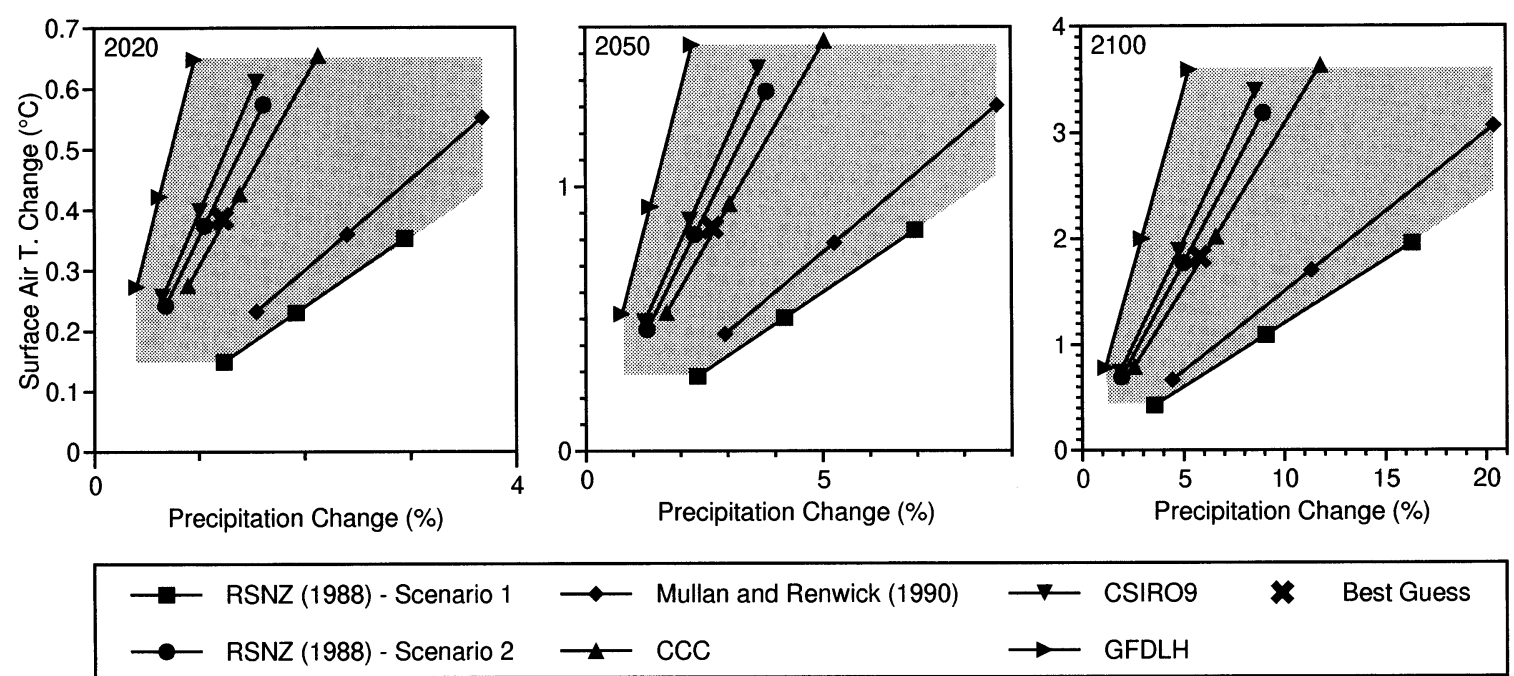

Fig. 6. Auckland region scenarios of annual change in surface air temperature and precipitation for 2020, 2050, and 2100. The 6 lines in each panel correspond to the 6 sources given in Table 3 . The 3 points on each line correspond to the minimum, bestguess, and maximum global warming scenarios, based on different emissions scenarios and values for $\Delta T_{2 \times}(T a b l e ~ 2)$. Shaded areas define envelopes enclosing the range of plausible climate futures (based on the sources used here). 'Best guesses' are the median of the 6 sources for emissions scenario IS92a and $\Delta \mathrm{T}_{2 \times}=2.5^{\circ} \mathrm{C}$

in PE per ${ }^{\circ} \mathrm{C}$ of surface air temperature warming. Fig. 7b shows the resulting scenarios of $\mathrm{PE}$ and precipitation derived by applying this 2 to $4 \%$ range to the temperature and precipitation scenarios in Fig. 7a. The $2 \%$ per ${ }^{\circ} \mathrm{C}$ change is applied at the cooler limit of each scenario and $4 \%$ per ${ }^{\circ} \mathrm{C}$ at the warmer end of the range. Applying $3 \%$ per ${ }^{\circ} \mathrm{C}$ to the best-guess surface air temperature increase for each scenario gives bestguess changes in PE of $1.2 \%$ (2020), 2.5\% (2050), and $5.5 \%(2100)$.

A further important source of uncertainty in the context of climate change scenarios for water resource applications is the effect of higher concentrations of $\mathrm{CO}_{2}$ on stomatal conductance, and hence PE. Reviews by Kimball \& Idso (1983), Cure (1985), and Morison (1985) indicate potential major increases in stomatal resistance to vapour diffusion with associated transpiration decreases of the order of 16 to $51 \%$ (Cure \& A cock 1986). If these changes were translated into comparable effects on evaporation in the field, the associated water resource impacts would be substantial (Aston 1984, Idso \& Brazel 1984, Wigley \& J ones 1985). However, other lines of argument suggest that the effect may be largely counterbalanced by negative feedbacks such as: increased leaf area index, increased leaf temperature, reduced regional humidity, and compensating increased evaporation from the soil surface ( arvis \& M cNaughton 1986, Gifford 1988, McNaughton \& J arvis 1991). Indeed, Samarakoon \& Gifford (1995) show that, for plants with a strong leaf area response but weak stomatal response to $\mathrm{CO}_{2}$ enrichment, evaporation can be enhanced. Anatomical adaptation possibly countering transpiration reduction has also been proposed (e.g. Woodward 1987).

Martin et al. (1989) note that $\mathrm{CO}_{2}$ enrichment in the open air has not yet been achieved for long enough to determine if results from stomatal conductance experiments are applicable to field conditions, nor whether effects will be persistent or transitory. A more recent review of field experiments by Korner (1996) indicates 'preliminary' evidence of a 'slight' reduction in water consumption per unit area for a doubling of $\mathrm{CO}_{2}$, confirming the conclusion of Gifford et al. (1996) that any reduction in whole system evaporation might be modest, or zero in the event of complete leaf area compensation. In short, the available evidence does not warrant confidence in any conclusion about significant $\mathrm{CO}_{2}$ enrichment effects on PE change. In view of this, the best guess adopted here is no change, but a revision of the PE lower limits of the 3 scenarios to zero is considered appropriate given the likely direction, but small scale, of any effect. The adjusted scenarios are shown in Fig. 7c.

The scenario envelopes and best guesses shown in Fig. 7c are the final form of the regional climate change scenarios used in this study, showing changes in $P$ and PE to be applied without seasonal differentiation. Given the scale of uncertainties at both the global and regional scales it is quite possible that future climate change may be outside the range shown here. Nevertheless, the scenarios shown represent the best available estimates of future climate change based on the current state of the science. They represent plausible climate futures. 

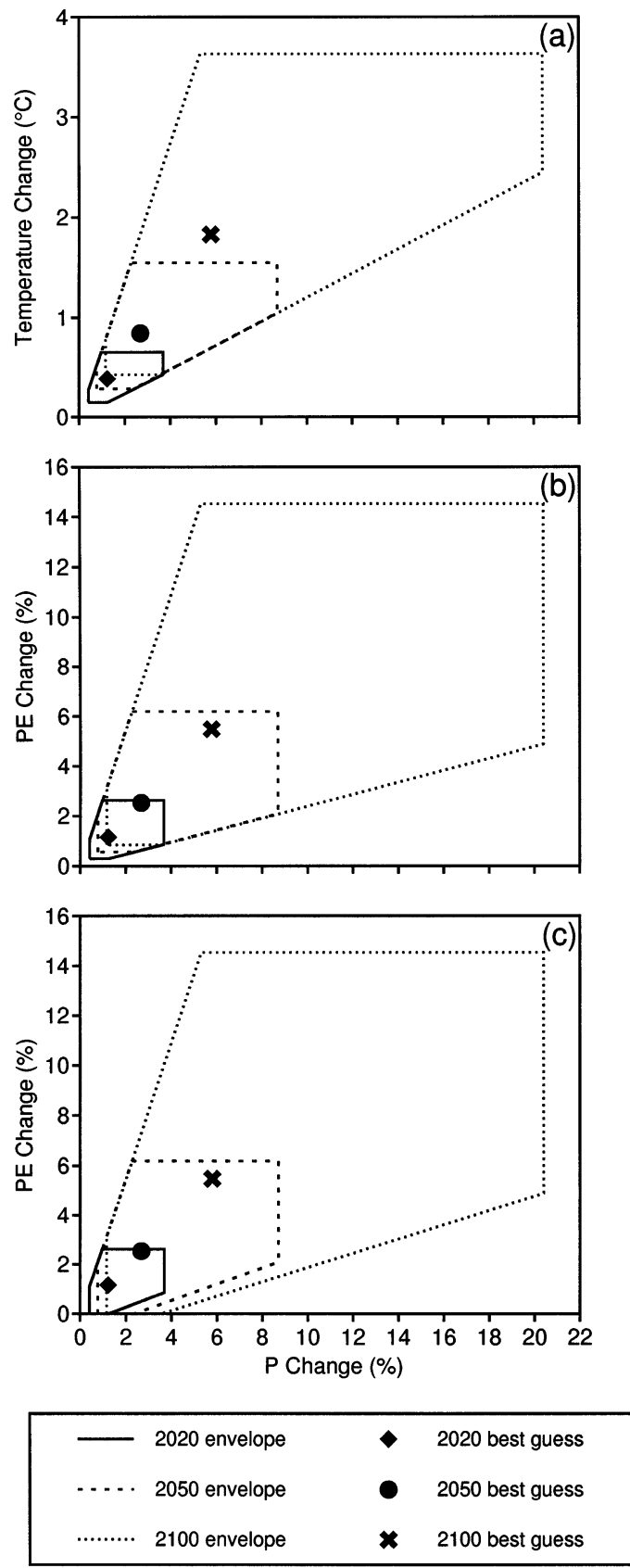

Fig. 7. Regional annual climate change scenarios for the Auckland region: (a) precipitation and temperature change scenarios from Fig. 6; (b) transformed into precipitation and $\mathrm{PE}$ change scenarios using a 2 to $4 \%$ increase in PE per ${ }^{\circ} \mathrm{C}$ increase in temperature; (c) adjusted for direct $\mathrm{CO}_{2}$ effects on stomatal conductance. Best-guess estimates are for $\Delta \mathrm{T}_{2 \times}=$ $2.5^{\circ} \mathrm{C}$ and emissions scenario IS92a

\section{THE BIOPHYSICAL TRANSFER FUNCTION}

Biophysical transfer functions used for climate change impact assessment must be capable of providing planners with relevant and reliable information, be applicable under a changed climatic regime, be able to cope with potential biophysical feedbacks, and be capable of being linked with scenarios of climate change. Consideration of those criteria in the water resource context (Klemes 1985, 1986) establishes process-based hydrological models as most suitable.

Accepting these prerequisites and the limitations imposed by them, the model development philosophy here follows the 'Occam's Razor' approach proposed by Betson \& Ardis (1978). No more than essential complexity is incorporated into the model structure and algorithms, the number of model parameters is kept to a minimum to avoid problems of overfitting ('decreased efficiency of estimation of parameters as model complexity increases'; Pilgrim 1986, p. 173S), and a modular/systems approach is taken to development. The latter involves breaking the model into component parts (e.g. interception) and treating them independently, as far as possible. This helps minimise interactions between processes and parameters (reducing overfitting problems) and facilitates component calibration independent of normal model fitting. Thus parameters in the interception 'module' are derived from independent field calibration (native forest), or set from values obtained from the literature (pasture), and are not revisited during model calibration proper.

The soil water regime and catchment water yield applications in this study impose different requirements on the hydrological model used as the transfer function. There are complex issues associated with differing spatial scales, the components of the hydrological cycle that need to be included, and the level of sophistication appropriate for each component (Fowler 1992). The approach adopted to handle these different requirements was to develop a daily water balance model (DWBM) capable of operation in either 'point' or 'catchment' modes, for soil water regime and catchment water yield applications respectively. In the latter case the model most closely fits the 'conceptual lumped-parameter' category of Leavesley (1994), although it could also be viewed as a single element of a 'process-based distributed-parameter' model.

A brief outline of the DWBM is given in Section 5.1. Calibration and verification are summarised in Section 5.2. The detailed rationale, analyses and commentary from which these summaries are derived can be found in Fowler (1992, Chapters 6 to 9).

\subsection{Outline of the DWBM}

Fig. 8 is a schematic representation of the DWBM. Intended for application in locations where rainfall is the only significant precipitation input, the DWBM operates with a daily iteration time step, and is driven 


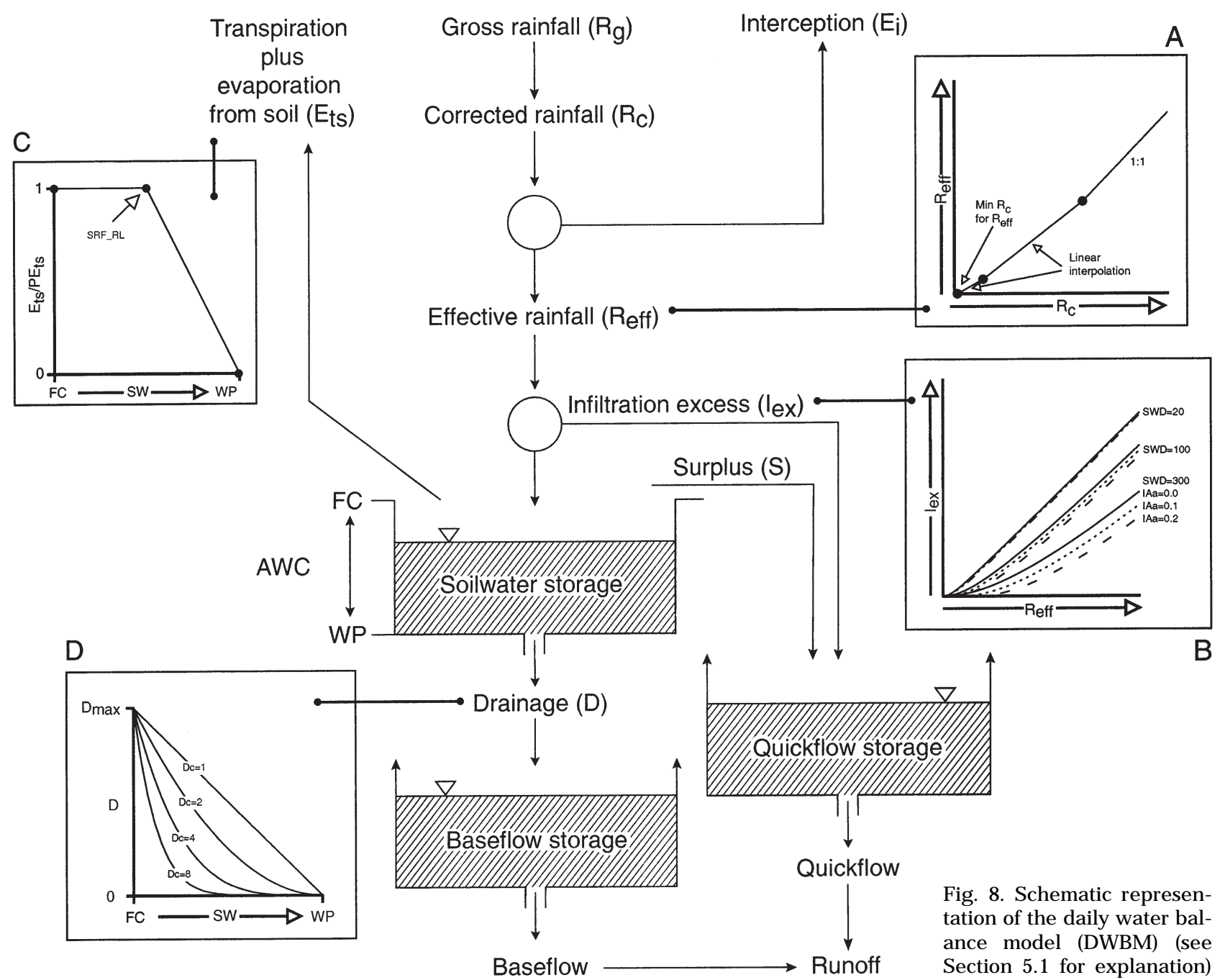

by time series of corrected rainfall $\left(R_{c}\right)$ and $P E . R_{c}$ is derived from recorded gross rainfall $\left(R_{g}\right)$, corrected for wind-field deformation and evaporation losses following Sevruk (1982). Based on a review of the empirical literature and on field experimentation, corrections vary depending on the specific raingauges used at various sites. But for the wind regime typical of lowland areas in the Auckland region, corrections of the order of 10 to $15 \%$ were found necessary, the bulk associated with wind-field deformation effects.

$R_{c}$ is partitioned between interception (I) and effective rainfall $\left(R_{\text {eff }}\right)$ arriving at the soil surface, calculated using a non-linear empirical relationship between $R_{\text {eff }}$ and $R_{c}$ (Fig. 8, Inset A). One parameter sets the lower limit below which no effective rainfall is modelled and 2 points $(x, y)$ define the relationship up to the point where any additional rainfall is assumed to be effective.

$\mathrm{R}_{\text {eff }}$ arriving at the soil surface is partitioned between infiltration and infiltration excess $\left(\mathrm{l}_{\mathrm{ex}}\right)$. Based on a mod- ification of the 'SCS curve number method' (USDA 1972), $I_{e x}$ is a function of $R_{\text {eff, }}$ the soil water deficit (SWD), soil surface storage capacity, and soil infiltration capacity. A parameter $\left(\mathrm{IA}_{\mathrm{a}}\right)$ sets how effectively available storage capacity is utilised ('initial abstraction' in hydrological jargon). The net effect (Fig. 8, Inset $B$ ) is that significant $I_{e x}$ requires very wet soils and/or very heavy precipitation.

Soil water storage is defined in terms of available water capacity (AWC), the difference between field capacity (FC) and wilting point (WP). Input to soil water storage is $R_{\text {eff }}-I_{\text {ex }}$. Outputs are slow drainage to groundwater (D), evaporation in the form of transpiration and diffusion of water directly from the soil (jointly $\left.E_{t s}\right)$, and surplus (S). $S$ is a pooled flux representing rapid drainage from soils between saturation and FC, plus any additional infiltration excess when soil water content reaches saturation.

Drainage is a non-linear function of soil water content, based on Aston \& Dunin (1977). There are 2 ad- 
justable parameters. $D_{\max }$ defines daily drainage when the soil is at FC (drainage above FC modelled to occur in $1 \mathrm{~d}$ and handled through the surplus concept) and $\mathrm{D}_{\mathrm{c}}$ controls the steepness of the drainage curve. For a fixed value of $D_{\max }, D_{c}$ defines a family of potential drainage curves (Fig. 8, Inset D).

$E_{t s}$ is calculated as a non-linear function of potential dry canopy evaporation $\left(\mathrm{PE}_{\mathrm{ts}}\right)$ and soil water content. $P E_{t s}$ is derived from standard PE calculations from measurements over grass, accounting for vegetation dependence (M cNaughton \& J arvis 1983) via a parameter representing the $\mathrm{PE}_{\mathrm{ts}} / \mathrm{PE}$ ratio. Reduction of $\mathrm{PE}_{\mathrm{ts}}$ on raindays, reflecting the fact that energy used for $E_{i}$ is unavailable for $E_{t s}$, is accommodated by an additional parameter reflecting the $\mathrm{E}_{\mathrm{i}} / \mathrm{PE}_{\mathrm{ts}}$ ratio. Finally, $\mathrm{E}_{\mathrm{ts}}$ is calculated from $\mathrm{PE}_{\mathrm{ts}}$ by multiplying by a soil resistance factor (SRF) ranging from zero at WP to 1 at FC, reflecting the choking back of evaporation as the soil dries. The relationship between SRF and soil water content is defined by a parameter (SRF_RL) setting the percentage of AWC evaporated at the potential rate (Fig. 8, Inset C). For drier conditions SRF declines linearly to zero at WP.

The lower 2 stores in Fig. 8 relate only to catchmentmode application of the DWBM. These are highly empirical components of the model, but serve only to route water available for runoff $\left(l_{e x}, S, D\right)$ out of the catchment. The water balance is unaffected, other than through minor changes in amounts carried forward over arbitrary time periods. D is routed to a baseflow store of unlimited capacity, from which baseflow is modelled as a non-linear function of storage, using the 2-parameter recession curve equation of Boughton (1986). $I_{\text {ex }}$ and $S$ are routed to a quickflow store, from which quickflow is modelled in the same manner as baseflow, but with parameters set to give a much more rapid evacuation of the store.

\subsection{Calibration and verification}

\subsubsection{Point mode}

The DWBM described above was calibrated and verified in 'point mode' against time series of soil water measurements at 3 pasture sites at Kumeu Research Orchard (Fig. 1) using a standard split-record approach. The 3 sites are poorly drained silt loam soils, 2 with a pronounced peaty character and all with significant water table penetration of the rooting zone, persistent over winter. All sites are within $300 \mathrm{~m}$ of a high-quality meteorological observation site, recording daily precipitation and variables required to calculate PE. Pairs of neutron probe access tubes were installed at each of the 3 sites to a depth of $1.4 \mathrm{~m}$ and measurements were made at approximately weekly intervals over a period of $16 \mathrm{mo}$. Soil water content in $0.1 \mathrm{~m}$ layers was constructed from this data set and integrated over the soil profile to a depth of $1.0 \mathrm{~m}$.

Initial values for DWBM parameters were established from review of the literature and, where possible, analysis of the soil water data time series. Interception parameters were based on results reported for short crops by Feddes et al. (1978) and Bultot \& Dupriez (1985). The infiltration excess and drainage routines in the DWBM were disabled in the initial setup, on the basis of no observed surface ponding in $16 \mathrm{mo}$ and the fact that water balance models have often been successfully applied without a drainage function. AWC was derived from comparison of soil water content profiles during dry versus wet conditions. Parameters defining the ratios $P E_{t s} / P E$ and $E_{i} / P E_{t s}$ were both set equal to 1 and were not optimised, because the vegetation cover is the same as for reference $P E$ and because a complementary relationship between $E_{i}$ and $P E_{t s}$ can reasonably be assumed for short crops (M onteith 1965). The parameter setting the threshold soil water content at which $E_{t s}$ drops below $P E_{t s}$ (SRF_RL) was set equal to $100 \%$ of AWC (i.e. $E_{t s}=P E_{t s}$ when any soil water available) on the basis of little observed attenuation of the summer drying curve. Runoff components of the DWBM were suppressed.

Calibration of the DWBM at each site was based on visual comparison of plots of modelled and measured SWD and the root mean square error (RMSE). Results obtained for the initial model runs were very poor (RMSE: 17 to $49 \mathrm{~mm}$ ), largely due to the effect of water table penetration of the root zone. Activation and calibration of the drainage routine (initial parameters values established from examination of drying curves over winter when evaporation is minimal) and reduction of SRF_RL to 30-60\%, depending on site, largely resolved this error (RMSE: 12 to $17 \mathrm{~mm}$ ). Five of the 6 (2 sets of 3 ) verification statistics are comparable (RMSE: 14 to $18 \mathrm{~mm}$ ) to the calibration results. The sixth (RMSE: $38 \mathrm{~mm}$ ) was rejected as unacceptable. One set of verification statistics was consistently superior (RMSE: 14 to $18 \mathrm{~mm}$ ) to the other set and were accepted as reasonable. Fig. 9 shows the corresponding verification plots.

\subsubsection{Catchment mode}

The DWBM was calibrated and verified in 'catchment mode' against time series of throughfall (14 mo), soil water (17 mo, $1.4 \mathrm{~m}$ depth), and runoff ( $21 \mathrm{mo}$ ), at a 1.3 ha native forest catchment, Huapai Scientific Reserve (Fig. 1). The site is on the edge of a spur at the 

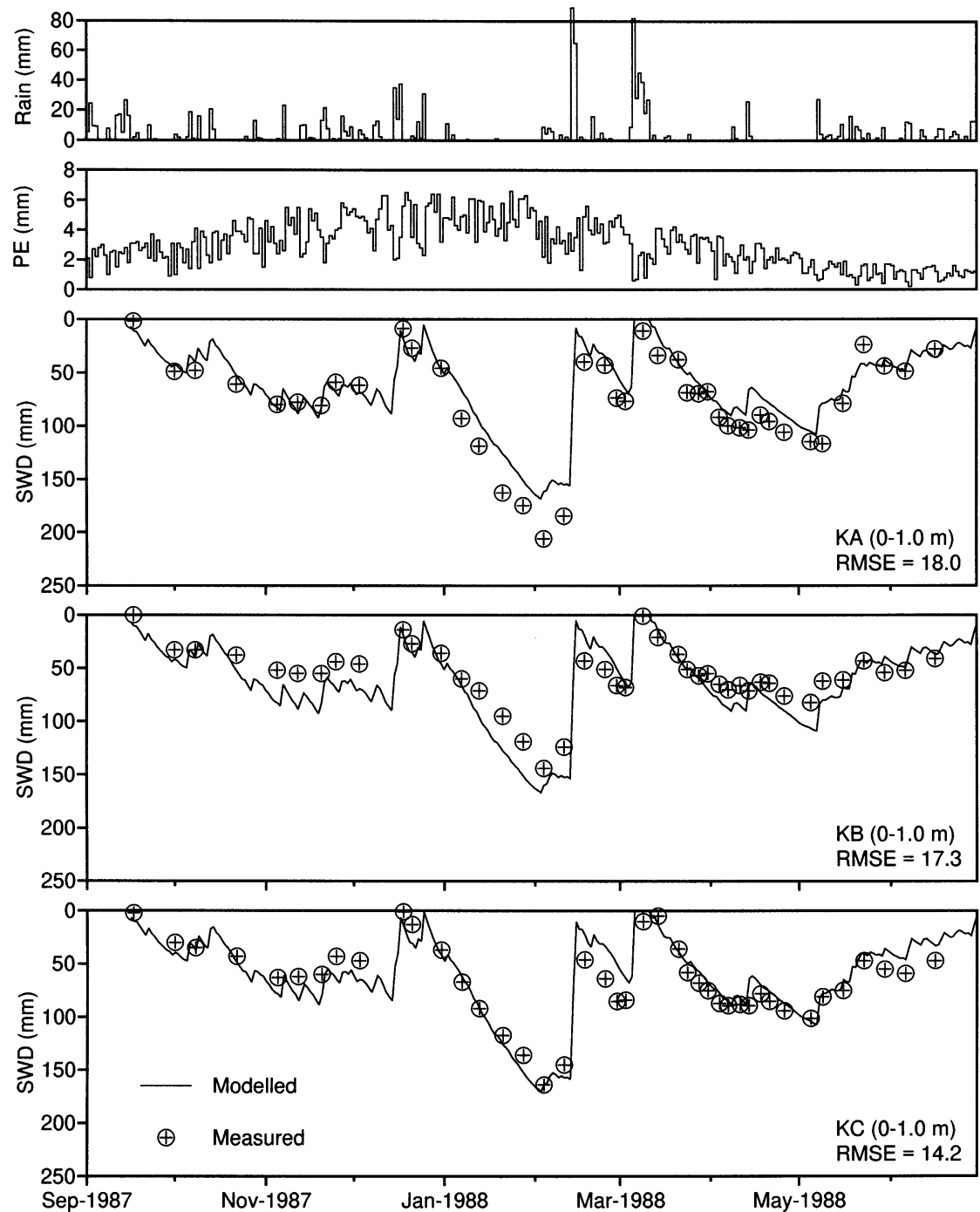

Fig. 9. Verification performance of the DWBM in 'point mode' at 3 pasture sites at Kumeu Research Orchard (KA, KB, KC). SWD: soil water deficit. RMSE: root mean square error. Note: model calibration was over the period March-September 1997

calibration of these analytically derived parameters was undertaken. Initial values for AWC, IA $D_{\max }$, and $D_{c}$ were derived from analysis of calculated catchment SWD integrated over nominal depths of 1.0 and $1.4 \mathrm{~m}$. The ratio $\mathrm{PE}_{\mathrm{ts}} / \mathrm{PE}$ was set equal to 0.65 , based on cited figures in the literature of 0.32 to 0.80 (Rutter 1968, Black 1979, Shuttleworth \& Calder 1979, McNaughton \& J arvis 1983). The ratio $E_{i} / P E_{t s}$ was set equal to 3.0, based on an upper limit of about 5.0 (M onteith 1965), but a value of about 3 being more appropriate for daily modelling (Blake 1975, Stewart 1977), due to complete saturation of the canopy being both unusual and transient. SRF_RL was set equal to $70 \%$ of $A \bar{W} C$, based on values cited by Black (1979), Dunin et al. (1985) and Roberts (1983). Initial values for recession curve parameters were derived from analysis of relevant sections of the recorded catchment hydrograph.

Calibration of the DWBM was over $17 \mathrm{mo}$, including all $17 \mathrm{mo}$ of soil water data and $13 \mathrm{mo}$ of runoff data. Verification was against a further 8 mo of runoff data only, immediately following this period, from mid-winter through to the end of summer. Calibration focused on visual comparison of time series plots of modelled and measured soil

northern limits of the Waitakere Ranges with slope angles exceeding $30 \%$ in places. Soils are predominantly silty clay loams. Rainfall was recorded by 2 automatic raingauges outside the catchment; other meteorological data was obtained from the Kumeu site, $8 \mathrm{~km}$ away. Throughfall was recorded at 6 sites under different canopy structures. Soil water was derived from neutron probe measurements at 10 access tubes at various topographic positions, averaged to give a mean catchment value. Runoff was recorded at a 90-degree v-notch weir.

Interception parameters were derived by pooling results obtained from analysis of the throughfall data at each of the 6 sites, with a small adjustment for stemflow based on Blake (1975) and Sangster (1986). No water content and runoff (both measured in $\mathrm{mm}$ ), aided by RMSE statistics (RMSE_SW, RMSE_Q) for each and modelled runoff as a percent of measured $(\mathrm{Q} \%)$, the latter being particularly important for water resource applications. Calibration statistics were: RM SE_SW = $21 \mathrm{~mm}$; RMSE_Q $=1.1 \mathrm{~mm}$; Q $\%=102 \%$. For the verification period (Fig. 10), RM SE_Q is higher (2.3 $\mathrm{mm}$ ) but Q\% is lower (101\%).

\subsubsection{Waitangi Catchment}

Because of the intended application of the DWBM to catchments up to several orders of magnitude larger than the Huapai Catchment, a further calibration/ 
Fig. 10. Verification performance of the DWBM in 'catchment mode' at Huapai Scientific Reserve
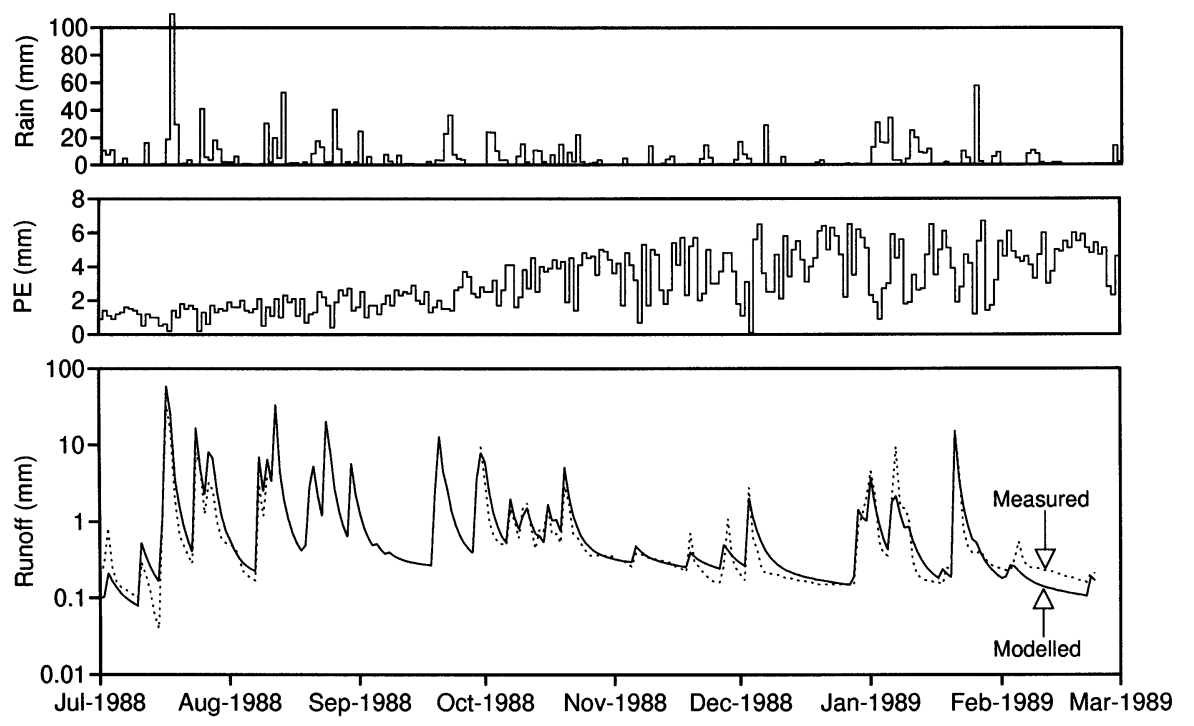

verification test was undertaken on the $17.6 \mathrm{~km}^{2}$ Waitangi River Catchment (Fig. 1). Located in the south of the region this is a predominantly pasture catchment with flat to rolling topography and broad drainage divides. Rainfall is recorded at the catchment outlet and flow is recorded at a 90-degree $v$-notch weir with 1: 5 concrete wing-walls. PE is from A uckland Airport, $25 \mathrm{~km}$ to the north.

Initial values for most DWBM parameters were estimates based on previous experience, information about the catchment provided in MWD (1970), and a review of the modelling literature. The exceptions were the runoff parameters where estimates were based on analysis of sections of the hydrograph.

The DWBM was calibrated against 38 mo of runoff data and verified against an additional $44 \mathrm{mo}$. The data quality of the 2 periods is similar but the calibration period is characterised by lower flows. Given the expectation of regional climate change towards wetter conditions, calibration on the drier period was considered most appropriate. Calibration statistics are RMSE_Q $=1.2 \mathrm{~mm} ; \mathrm{Q} \%=101 \%$. Verification statistics are comparable at RMSE_Q $=0.9 \mathrm{~mm}$ and $\mathrm{Q} \%=$ $101 \%$. However, satisfaction with these statistics is somewhat tempered by examination of the plots for the verification period shown in Fig. 11. Winter through summer ( une to February) runoff is simulated well but underestimation of baseflow is apparent in Autumn (March to May), emphasised by the log scale used. This is not consistent from year to year but is particularly serious in 1974 when simulated flows as low as $0.04 \mathrm{~mm}$ contrast with measured flows of $0.2 \mathrm{~mm}$. Apart from this qualification, the simulation results are considered acceptable, especially given that the rainfall input is a single raingauge at the outlet.

\subsubsection{Calibration/verification conclusions}

The credibility of any assessment of potential climate change impacts on water resources rests in turn on the credibility of both the climate 'input' and the transfer function (hydrological model here) used to simulate impacts. The relatively simple approach to modelling the soil water regime here has a long history and has proven to be robust. Successful application even in the relatively difficult Kumeu Research Orchard environment under conditions of significant water table influence give grounds for confidence that simulation results from such models are meaningful, especially under the simpler free-draining highly permeable soils more typical of agricultural applications.

Model performance in terms of runoff is more mixed. On the positive side, getting the total water budget right does not seem to be a problem, with modelled flows within $1 \%$ of measured for both verification tests. However, the baseflow failure in the case of the larger catchment means that no credible results can be presented related to minimum low-flow conditions, used extensively by water resource planners for water allocation decisions. Instead, runoff simulations using the DWBM are limited to totals over periods at the seasonal or longer scale and, even here, March to May results need to be interpreted with caution.

\section{IMPACT ASSESSMENT}

\subsection{Impact assessment methodology}

Impact assessments in this paper are nested within a more general set of sensitivity analyses, presented here as response surfaces -2 -dimensional represen- 

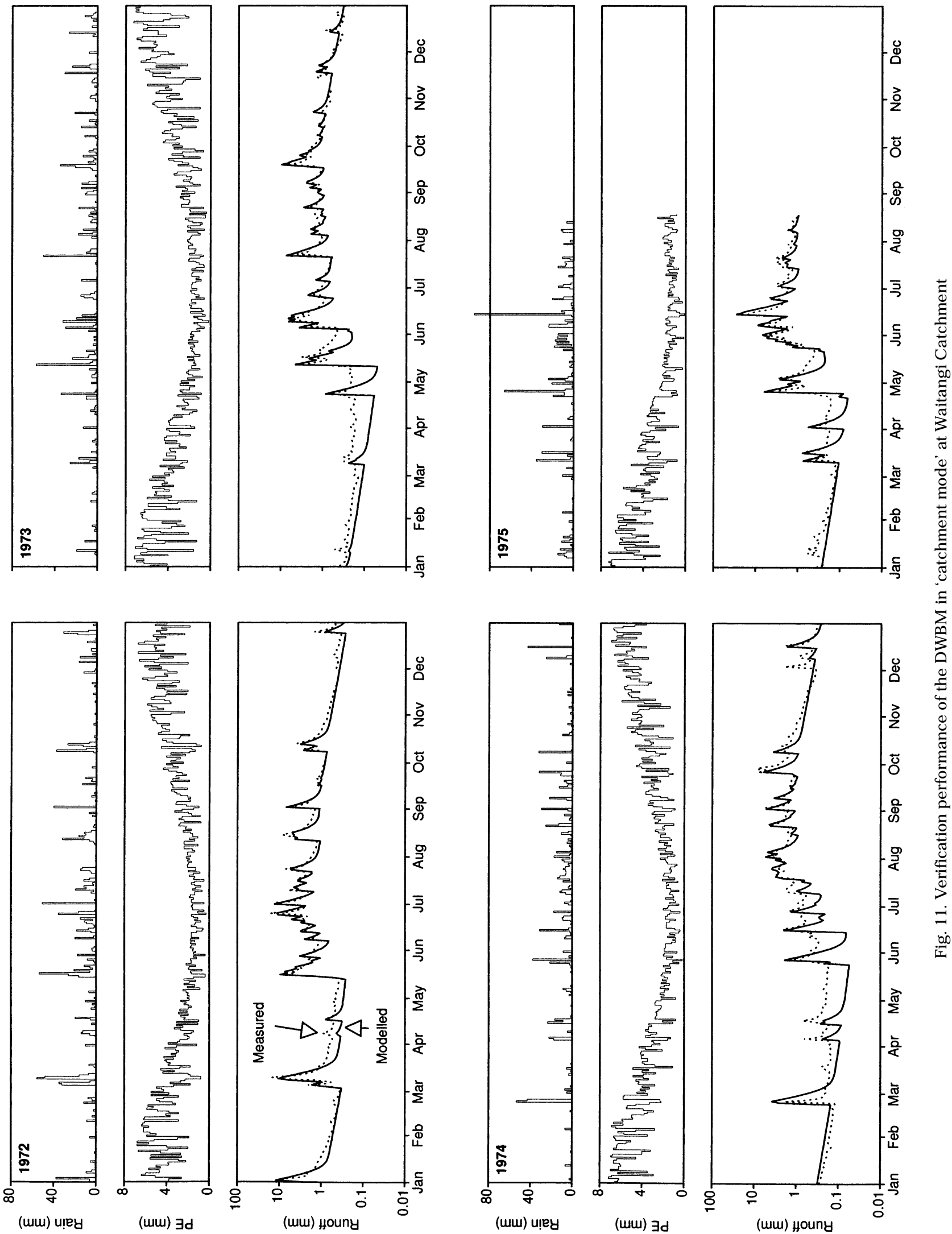
tations of the response of selected impact variables (runoff and SWD) to joint changes to precipitation (P) and PE. Response surfaces are derived by making multiple runs of the DWBM in which the $P$ and PE input time series are adjusted through a range of values $(-20$ to $+40 \%$ in $10 \%$ increments), and fitting isopleths through the matrix of response variable results. All adjustments to the input time series are applied on a daily basis throughout the year with no seasonal differentiation. Thus, it is assumed that a $20 \%$ increase in $P$ would be experienced as a $20 \%$ increase on each precipitation day rather than as an increase in the number of days.

Different response variables show different patterns of sensitivity to climate change, and patterns are likely to differ seasonally, with site characteristics (especially vegetation and soil type), and with regional differences in the climatic regime. Various permutations are investigated by constructing multiple seasonal response surfaces for different sets of climate input data and site characteristics. Differences in climate regime are handled by driving the DWBM with adjusted $\mathrm{P}$ and PE data (1972 to 1985) from Auckland Airport and Pukekohe (Fig. 1), sites close to the regional climate regime limits for lowland areas (Fig. 2). Different environmental conditions are handled by running the DWBM for different vegetation covers, soil water storage capacities, and drainage regimes. Key results only are presented here; these are extracted from detailed analyses presented in Fowler (1992).

Having constructed the seasonal response surfaces for mean SWD and total water yield, the first stage of the impact assessment is a relatively straightforward task of superimposing the scenario envelopes given in Fig. 7c. Use of summary statistics (e.g. seasonal mean SWD) in this way is necessary to achieve the desired integration over a range of environmental conditions. But, on 2 counts, sole reliance on response surfaces would give a somewhat limited perspective of potential climate change impacts. Firstly, response surfaces provide no indication of the significance of simulated changes in mean conditions. Secondly, exclusive focus on mean conditions is inconsistent with the widely held view amongst climate change researchers that impacts are more likely to be experienced through changes in the frequency of extremes than through shifts in the mean. These concerns are dealt with here through frequency analyses (specifically cumulative probability plots) of the annual values of simulated impact variables (cf. Whetton et al. 1993). The significance of simulated changes in mean conditions (response surface results) are assessed relative to the inter-annual variability shown in the cumulative probability plots, while implications for more extreme conditions are ascertained from examination of changes at the 'tails' of the plots. The 5 yr event ( $20 \%$ exceedance probability) is the focus of this latter analysis due to the prominence of this temporal threshold in regional water resource planning.

Seven frequency analyses are undertaken for each seasonal response surface: a baseline analysis using unadjusted input data (termed 'current climate') and 2 analyses for each of the 3 scenario dates. These frequency analysis pairs are intended to represent the bounds of an envelope of plausible impacts. Accordingly, they are derived for those combinations of $P$ and PE indicated by the scenario overlays to give the widest range of impacts. For SWDs the analysis focuses on the change in frequency of the seasonal mean SWD expected once in $5 \mathrm{yr}$ under the current climate, i.e. how more or less common we might expect this relatively rare event to be. For seasonal water yield, potential impacts are quantified as a flux change, specifically the change in magnitude of the $5 \mathrm{yr}$ seasonal low yield (80\% chance of being equalled or exceeded).

\subsection{Soil water results}

Response surfaces in Fig. 12 show the sensitivity of simulated mean seasonal SWDs to climate change when the DWBM is set up for a hypothetical pasture site and run using daily $\mathrm{P}$ and PE data from Auckland Airport. Isopleths represent the interacting impacts of changes in P and PE on mean seasonal SWDs. Isopleth orientation indicates relative sensitivity to changes in $P$ and PE: slopes less than $45^{\circ}$ (DJ F [December-February], SON [September-November]) indicate greater sensitivity to PE than $\mathrm{P}$; steeper lines (MAM [March-May], JJA [J une-August]) indicate greater sensitivity to $P$. Isopleth spacing indicates sensitivity to climate variation. The wider DJ F spacing of the isopleths with increasing $\mathrm{PE}$ and decreasing $\mathrm{P}$ is primarily due to the fact that further drying of the soil is constrained by the upper SWD limit of $150 \mathrm{~mm}$ (AWC) and by the increasing difficulty of further water extraction as that limit is approached.

The climate change scenarios (Fig. 7c) predominantly entail joint increases in $\mathrm{P}$ and $\mathrm{PE}$. In terms of the soil water regime, these must counter each other to some extent. The scenario envelope overlays on the seasonal SWD response surfaces (Fig. 9) indicate that, for the climate regime represented by Auckland Airport, the combined changes in P and PE largely cancel each other out. Scenario best guesses lying parallel to the SWD isopleths indicates only minor changes in all seasons while the fact that the envelopes for all 3 scenario dates straddle the isopleths means that even the direction of change is uncertain. 

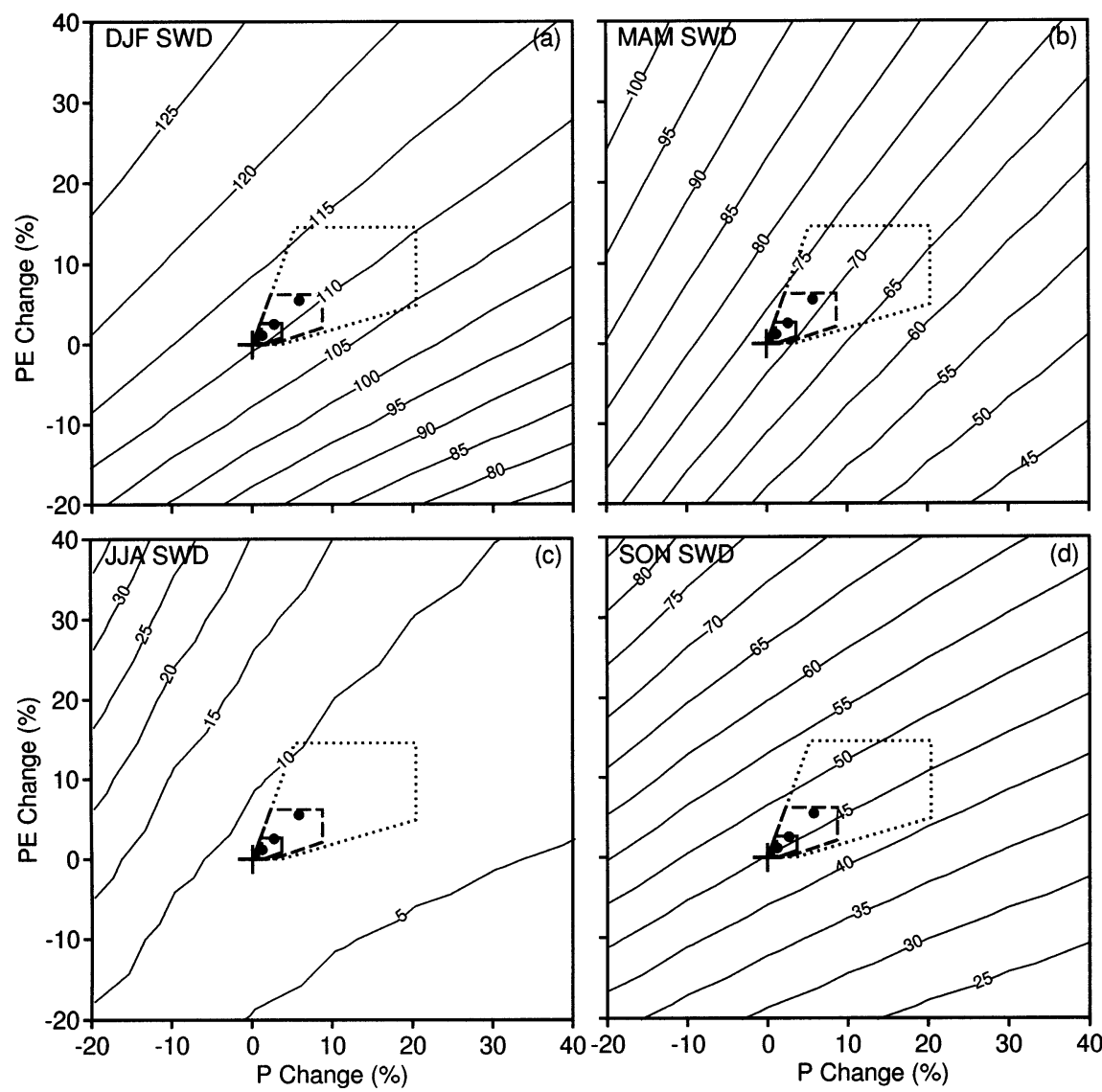

Fig. 12. Response surfaces of simulated mean seasonal SWDs for Auckland Airport. Derived for a hypothetical pasture site (available water capacity, AWC $=150 \mathrm{~mm}$ ) and with precipitation (P) and $\mathrm{PE}$ changes applied on a daily basis. Results are averaged over 13 DJ Fs (DecemberFebruary) and 14 MAMs (MarchMay), JJAs (J une-August), and SONs (September-November) (1972 to 1985). The DWBM was run for each $10 \%$ change in $\mathrm{P}$ and $\mathrm{PE}$, with the isopleths of mean seasonal SWD fitted through the resulting $7 \times 7$ data matrix for each panel. Regional climate change scenarios from Fig. 7c are superimposed for 2020 (solid line), 2050 (dashed line), and 2100 (dotted line). The 3 larger dots in each graph denote the respective best-guess estimates for each scenario, also from Fig. 7c. +: current climate (P, PE unadjusted)
Fig. 13 shows cumulative probability curves derived for unadjusted input data and for the 2 points on each scenario envelope in Fig. 12 indicating the maximum range of simulated impacts. The 7 curves plotted for each panel give the probability of a given seasonal mean SWD being equalled or exceeded. One curve is derived by running the DWBM with the $P$ and PE time series as measured ('current climate'), represented by the no change point in each panel in Fig. 12. The 'high' and 'low' curves for each scenario date are derived from analyses undertaken using percentage changes in $\mathrm{P}$ and $\mathrm{PE}$ corresponding to the extreme simulated seasonal mean SWDs indicated by each scenario overlay. For example, the outermost (2100) curves in Fig. 13a correspond to the points on the scenario envelopes in Fig. 12a showing greatest $(115.7 \mathrm{~mm})$ and least (104.7 mm) mean DJ F SWD.

A notable feature of Fig. 13 is the fact that for all 3 scenario dates the pairs of cumulative probability curves straddle the curves for current climate in all seasons and across the full range of simulated SWDs. This indicates that the impact of climate change on more extreme conditions is qualitatively similar to the response pattern for mean conditions shown in Fig. 12 (i.e. uncertain direction of change). Fig. 13 also reinforces the contention that best-guess changes in mean seasonal SWD are minor for all combinations of scenarios and seasons. Changes of less than $2 \mathrm{~mm}$ are clearly insignificant relative to interannual variability of several 10s of mm shown in Fig. 13. Results for MAM (Fig. 13b) are a little more skewed about the current climate curve, indicating that a change to wetter soils is more likely in this season.

Change in the frequency of events with a prescribed return period under current climate is a useful measure of the significance of simulated impacts. For example, the SON current climate curve in Fig. 13d indicates that the $5 \mathrm{yr}$ maximum seasonal mean SWD ( $20 \%$ exceedance probability) is approximately $57 \mathrm{~mm}$. The potential impacts envelope for 2100 indicates that by 2100 a mean SWD of this size may occur in 12 to $50 \%$ of years (i.e. become a 2 to $8 \mathrm{yr}$ event). Again, the direction of change is uncertain and major changes are unlikely, at least until many decades into the future.

The scale of potential climate change impacts on the soil water regime is summarised in terms of percentage changes in the frequency of $5 \mathrm{yr}$ maximum seasonal mean SWDs. Results derived using Auckland Airport climate data are presented in Fig. 14a by season and scenario. Simulated changes in frequency by 2020 are less than $18 \%$ across all seasons, with reductions (5 to 


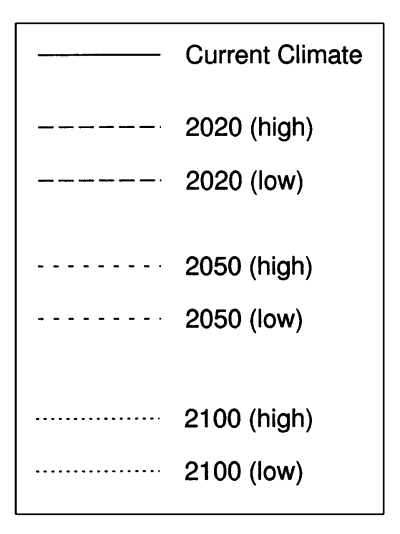

Fig. 13. Cumulative probability plots of simulated seasonal mean SWDs for Auckland Airport for current climate and for the 2020 , 2050, and 2100 scenarios. The 2 lines for each scenario correspond to the maximum range of simulated mean seasonal SWDs, indicated by the superimposed regional climate change scenario envelopes in Fig. 12
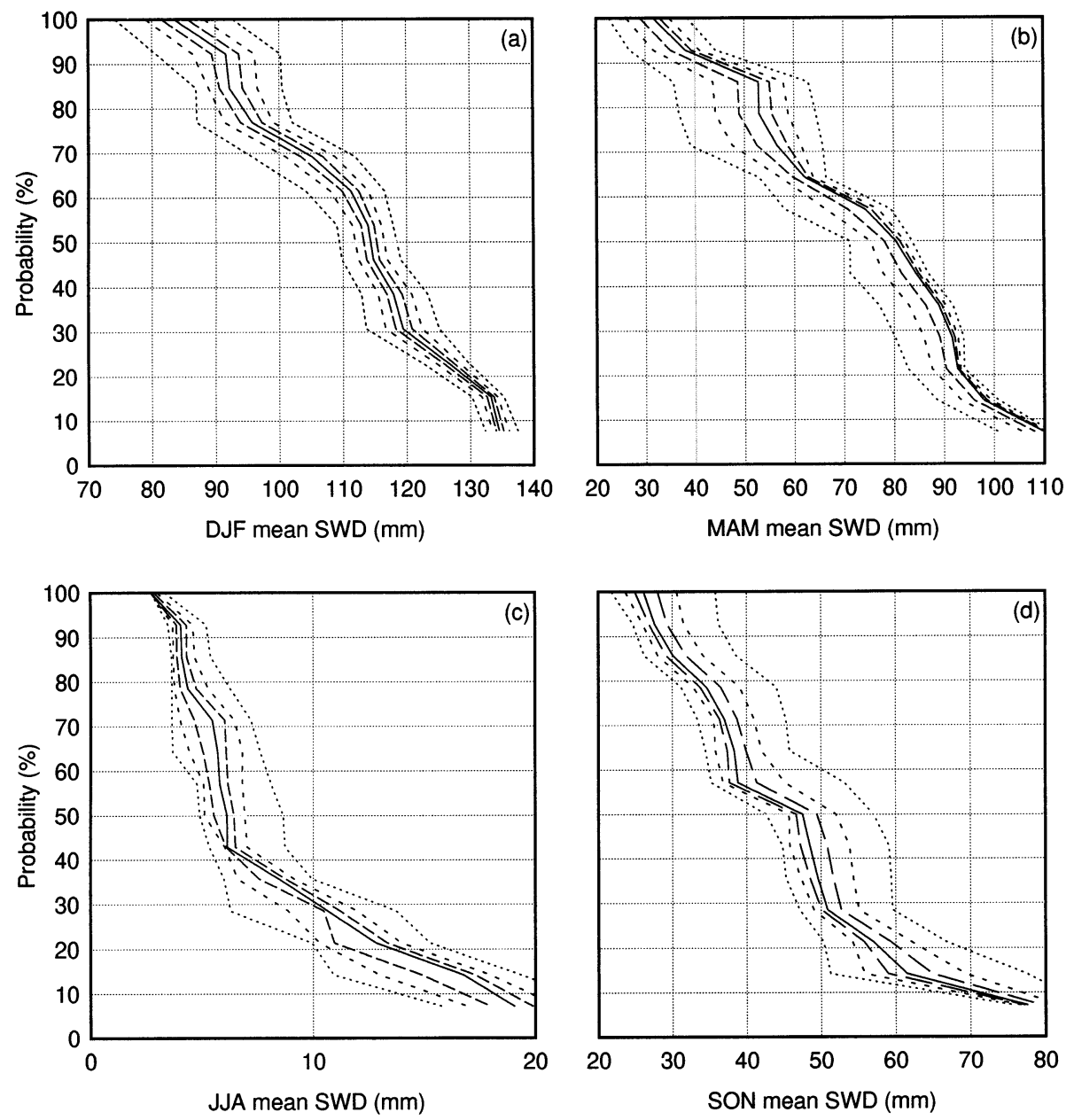

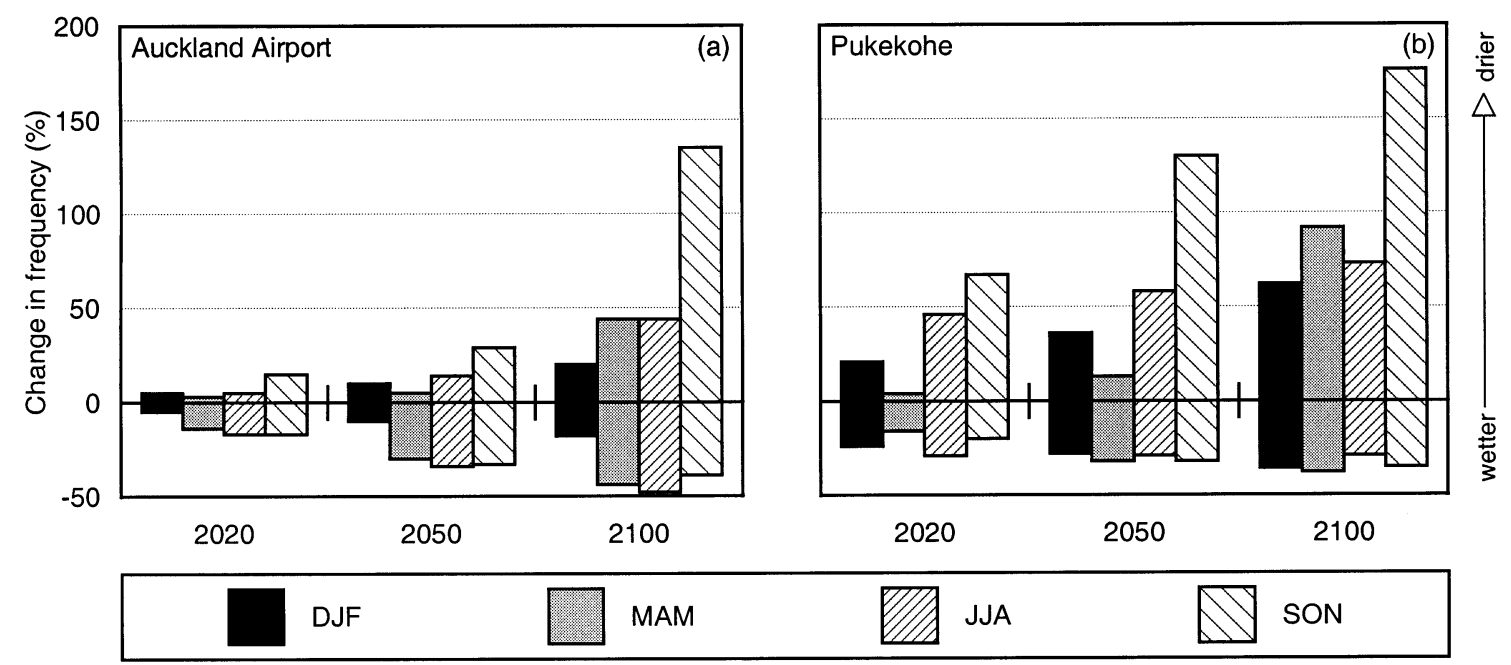

Fig. 14. Percent change in the frequency of the simulated 5 yr maximum seasonal mean SWD at (a) Auckland Airport and (b) Pukekohe for 3 regional climate change scenarios 

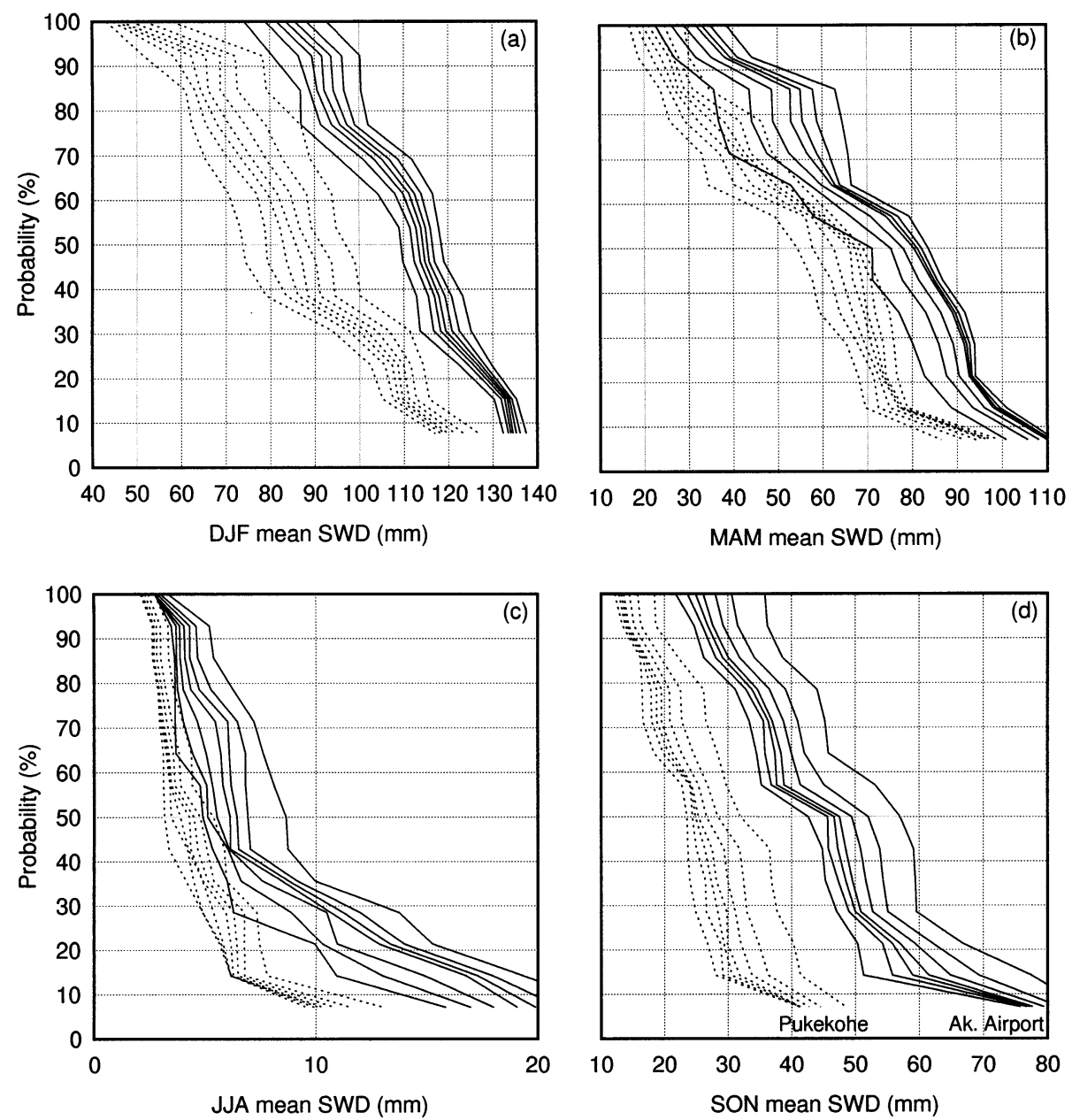

Fig. 15. Cumulative probability plots of simulated seasonal mean SWDs for Auckland Airport (solid lines, plotted in detail in Fig. 13) and Pukekohe (dashed lines) for current climate and for the 2020, 2050, and 2100 scenarios. The middle curve in each set of 7 corresponds to current climate and is bounded by curve pairs for 2020,2050 , and 2100 respectively in the same pattern as shown in Fig. 13

$17 \%$ ) larger than increases (3 to $15 \%$ ). A similar pattern is evident in the results for 2050, with decreases (10 to $34 \%$ ) higher than increases (5 to $29 \%$ ). Increases ( 20 to $135 \%$ ) dominate over decreases (18 to $48 \%$ ) by 2100. The significance of changes in frequency (least in DJ F, greatest in SON) reflects the relative size of the simulated impact due to climate change compared to inter-annual variability.

Results presented thus far for Auckland Airport pertain to a specific climatic regime and combination of site factors. In order to assess the influence of the climatic regime on the results, the analysis was duplicated for the Pukekohe site. Response surfaces (not shown) are qualitatively very similar and the same conclusions are drawn. Cumulative probability curves are shown in Fig. 15 (dashed lines) together with the results for Auckland Airport (solid lines), previously plotted in Fig. 13. Percentage change in the frequency of the $5 \mathrm{yr}$ maximum seasonal mean SWD for Pukekohe is shown in Fig. 14b.

Pukekohe results are qualitatively similar to those presented in detail for Auckland Airport. In particular, the direction of simulated change for all 3 scenarios is uncertain for all seasons and across the full range of SWDs. However, in terms of inter-annual variability, it is apparent from Fig. 14 that the soil water regime is markedly more sensitive at Pukekohe, with changes by 2050 similar in magnitude to the 2100 results for Auckland Airport. Potential soil drying impacts are greater at Pukekohe than Auckland Airport. In the event of decreased dryness, Pukekohe may be more significantly affected than Auckland by 2020, but less so by 2100 . As with Auckland Airport, SON is the season with the greatest potential impacts, but potential DJ F impacts are clearly more important in the Pukekohe case. Higher relative sensitivity at Pukekohe reflects either the larger climate-related impacts (DJ F) or lower inter-annual variability (J JA, SON) shown in Fig. 15.

With the possible exception of SON changes from 2050, the simulated climate change impacts on the soil water regime shown in Fig. 14 are relatively small. This contention is reinforced by comparison of the potential impacts envelopes in Fig. 15 which clearly show that differences between sites under the current climate are much more significant across all seasons 
than the range of simulated impacts even by 2100 . In other words, even the most extreme climate change envisaged by 2100 would not be expected to make Pukekohe as 'dry' as present day Auckland Airport, or Auckland Airport as 'wet' as present day Pukekohe. Given the 110 yr scenario time scale, and the fact that the potential impacts envelopes in Fig. 15 represent the maximum range for each scenario, significant potential climate change impacts on the soil water regime would appear unlikely. Indeed, even by 2050, impacts may not be discernible from inter-annual variability.

A series of further simulation experiments were undertaken to determine the sensitivity of the impact results to variation in AWC, drainage from the soil profile, and vegetation cover. Results indicate higher sensitivity in DJ F and MAM as AWC increases (50 to $270 \mathrm{~mm}$ range used). Even substantial changes to the drainage component of the DWBM had negligible effect on simulated climate change impacts on the soil water regime in DJ F and MAM. Potential impacts in JJ A and SON increase slightly as the importance of the drainage flux declines. Relative sensitivity is higher under native forest than pasture in all seasons, particularly JJ A and SON. Reductions in soil dryness seem more likely than increases, but the key simulation results are unchanged: changes are mostly small and of uncertain direction.

\subsection{Runoff results}

Seasonal water yield $(\mathrm{mm})$ response surfaces are presented in Fig. 16, derived by running the DWBM with Auckland Airport climate data and parameter values for a native forest catchment (Huapai Experimental Catchment -1 of 2 catchments used to develop, calibrate, and verify the DWBM model in its catchment mode). Comparison with Fig. 12 reveals significant differences in the sensitivity of the soil water regime and catchment water yield to climate variation. Notably, the markedly steeper isopleths in Fig. 16 in all seasons indicates greater sensitivity to change in $\mathrm{P}$ than $\mathrm{PE}$. For example, whereas a $10 \%$ increase in PE decreases the mean winter water yield by less than $10 \mathrm{~mm}$, the same percentage change in $P$ gives an increase of $30 \mathrm{~mm}$.

Differences in the sensitivity patterns are reflected in the scale of simulated impacts. Most importantly, and in marked contrast to the soil water regime analysis, the direction of potential climate change impacts is
Fig. 16. Response surfaces of simulated mean seasonal water yield (Q) for Huapai Experimental Catchment. Derived for parameter values obtained from calibration of the DWBM at the site but using Auckland Airport climate data as input. Regional climate change scenarios from Fig. 7c are superimposed
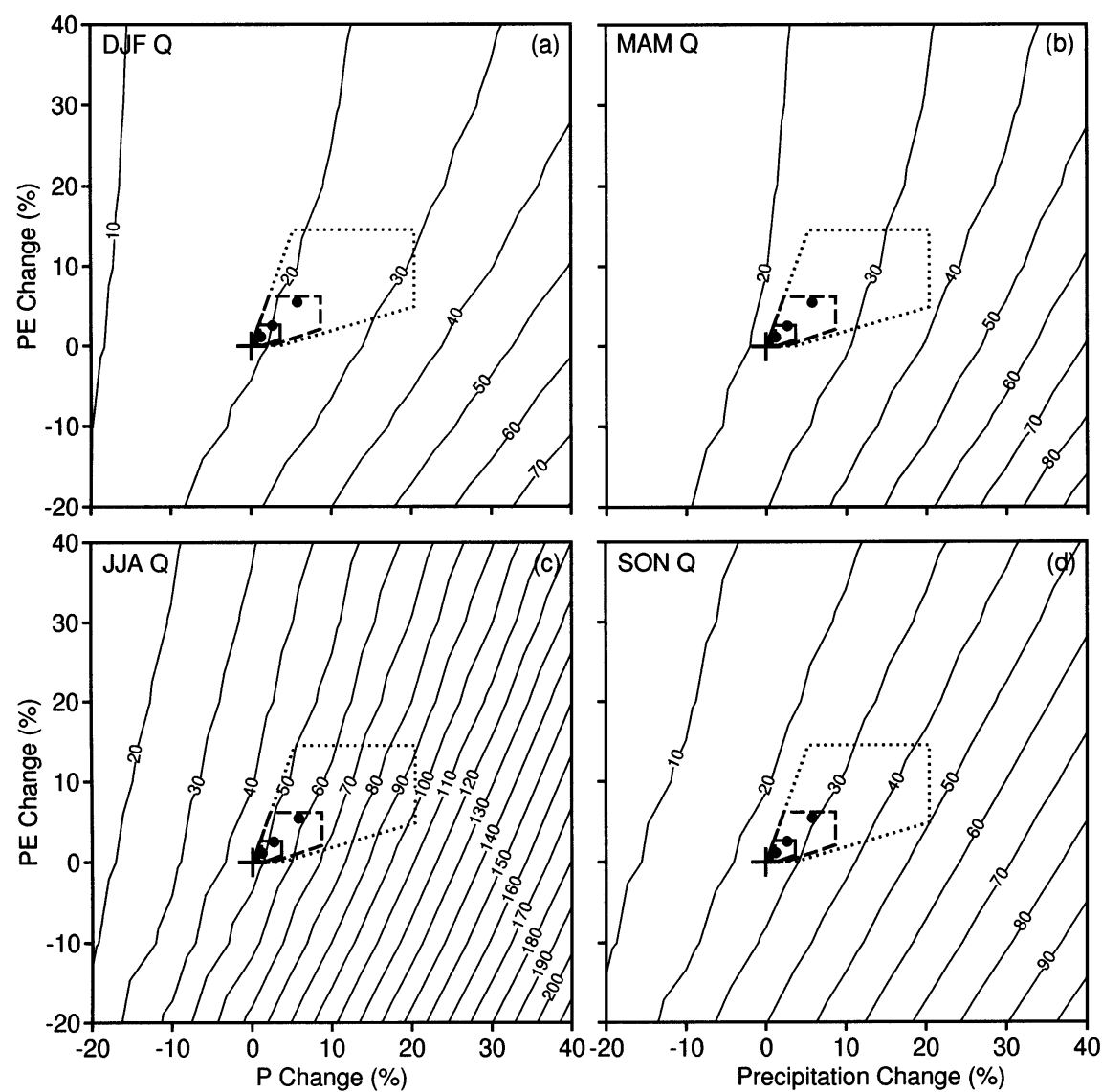
unambiguous. The scenario overlays indicate a range of potential impacts from near zero to substantial increases in seasonal water yield in all seasons, the only exception being SON for which a possible small reduction is indicated. In absolute terms, differences are greatest in J J A, the wettest season, with simulated increases greater than $50 \mathrm{~mm}$ by 2100 . In relative terms, potential increases in water yield are greatest in JJA and SON, but substantial in all seasons. These results suggest that, in terms of surface water resources, projected climate change is likely to be neutral to beneficial, with potential for a near doubling of the available resources by 2100 . It is also noteworthy that the direction of change simulated for the bestguess scenario estimates is consistent and potentially important across all seasons.

Cumulative probability curves of seasonal water yield (not shown) confirm the results of the response surface analysis that impacts associated with the $3 \mathrm{cli}$ mate change scenarios are likely to be in the direction of increased surface water resource availability. They also indicate that this is a consistent feature across the full range of inter-annual variability. In the context of the climate change scenarios used, there is little potential for reduced water yield in DJ F, MAM, or J J A, and only a minimal possible reduction in SON is indicated. In contrast, potential increases are substantial in all seasons, largest in absolute terms in relatively wet years, but comparable in percentage terms for the range of conditions represented by the Auckland Airport input data.

Because water allocation in the Auckland region is based on periods of low flow, change in water yield during relatively dry years is likely to be of most concern from a water resource planning perspective.
Fig. 17a shows percent change in the $5 \mathrm{yr}$ minimum seasonal water yield for native forest. Consistent with the results for mean water yield discussed above, simulated changes in water yield range from close to zero to large increases in all seasons, with the possibility of a small decrease in SON. Potential increases are substantial and may be important as early as 2020 .

Using Pukekohe climate data as input to the DWBM gives substantially larger potential impacts in absolute terms but broadly similar relative changes, including near-zero lower impacts bounds for each scenario. Seasonal differences are comparable with those simulated using Auckland Airport input data - lower relative changes over the drier seasons (DJF, MAM) and higher over the wetter seasons ( J A, SON).

Fig. 18 shows mean seasonal water yield response surfaces derived by again running the DWBM with Auckland Airport climate data but with model parameters altered to reflect a pasture catchment (Waitangi Catchment, also used to calibrate and verify the DWBM ). Given that the climate input data is the same, comparison with Fig. 16 indicates the sensitivity of potential impacts on catchment water yield to different catchment characteristics, especially in view of the contrast in vegetation cover (pasture vs native forest). The vegetation contrast is likely to be the primary reason for the differences shown, but a simplistic interpretation is not possible due to other differences between the 2 catchments (e.g. spatial scale, geology, morphology, soils).

Comparison of Figs. $16 \& 18$ indicates consistency in the sensitivity pattern and the direction of potential impacts for forest and pasture catchments. Similar isopleth slopes indicate similar sensitivity to percentage changes in P and PE across seasons, although with
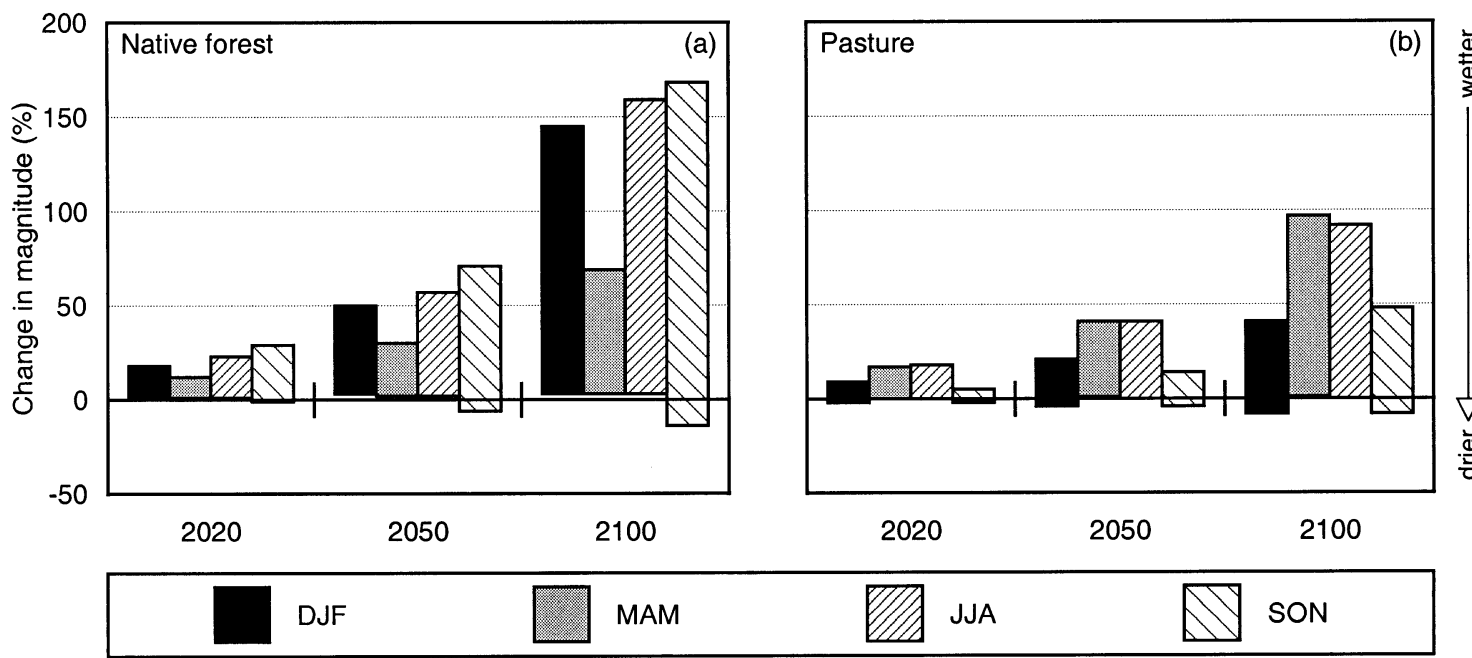

Fig. 17. Percent change in the 5 yr minimum seasonal catchment water yield for (a) native forest and (b) pasture for 3 regional climate change scenarios. Derived using Auckland Airport climate data as input to the DWBM 
Fig. 18. Response surfaces of simulated mean seasonal water yield (Q) for Waitangi Catchment. Derived for parameter values obtained from calibration of the DWBM at the site but using Auckland Airport climate data as input. Regional climate change scenarios from Fig. 7c are superimposed
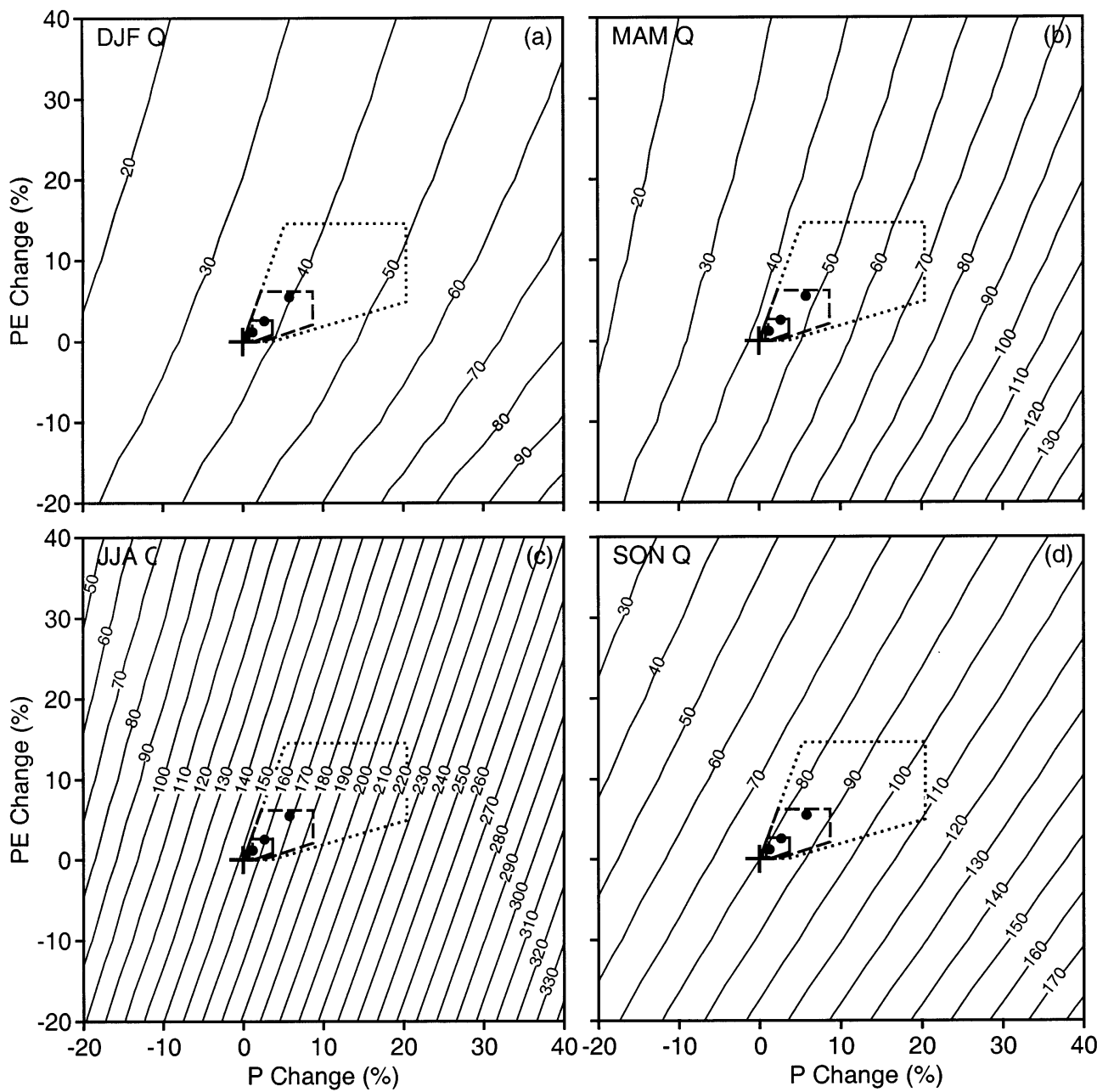

increased sensitivity to $P$ in J J A in the Waitangi simulation and reduced sensitivity in SON. Potential impacts on water yield identified by the scenario overlays for the Waitangi simulation are consistent with the Huapai results, ranging from near zero to substantial increases in the available surface water resources. As at Huapai, a small potential decrease is indicated in SON.

Comparison of the mean seasonal water yield simulated for unadjusted input data in Figs. 16 \& 18 (large pluses) indicates substantial differences in the unadjusted baseline analysis results. Simulated water yield is a factor of 2 larger at Waitangi in DJ F and MAM and a factor of 3 larger in J $\mathrm{A}$ and SON, primarily reflecting differences in interception loss. In absolute terms, potential impacts at the pasture site are about $50 \%$ larger.

Cumulative probability plots of seasonal water yield for the Waitangi simulation (not shown) indicate a broadly similar response pattern to Huapai in terms of inter-annual variability, but substantial and seasonally specific differences in terms of scale. Potential de- creases in water yield are small across the full range of seasonal water yields and for all seasons. The potential for reduced water yield is larger in SON than at Huapai and, in contrast to the Huapai simulation results, a possible small reduction in water yield in relatively dry DJ Fs is also indicated.

Fig. 17b gives the percent change in the magnitude of the $5 \mathrm{yr}$ minimum seasonal water yield for the pasture (Waitangi) simulation. An important result of this analysis is the confirmation of the forest (Huapai) results that potential reductions in catchment water yield are very small. Potential reductions are simulated for both DJ F and SON, compared to SON only in the Huapai experiment (Fig. 17a), but at 2 and $4 \%$ by 2020 and 2050, respectively, these potential decreases are minor, and only moderate $(8 \%)$ by 2100 . Also in agreement with the Huapai results, increases in water yield may be substantial, with simulated increases of up to $18 \%$ as early as 2020 .

A nother obvious feature of Fig. 17 is the significant difference between the results for the forest and pasture sites. With the exception of MAM, percentage 
increases in water yield are greater for the forest site, despite the fact that absolute changes are higher for pasture. The reason lies in the much lower baseline runoff from the forest catchment. Thus, although an increase in rainfall will have a larger absolute impact on runoff from the pasture catchment (due to lower evaporation), the smaller absolute runoff increase in the forest catchment will be larger in relative terms. From a water resource perspective, the lower DJ F percentage increase simulated for the pasture catchment, by a factor of 2 , is noteworthy.

\subsection{Summary and discussion of impact assessment results}

Table 4 summarises the more noteworthy impact assessment results presented in Sections 6.2 and 6.3. From a water resource planning perspective, the most important soil water regime results are the fact that the direction of future climate change impacts on the soil

Table 4. Summary of impact assessment results

\section{Soil water regime}

Direction of change uncertain

- All seasons, scenarios, climate regimes, and site characteristics

Best guess is negligible change

- All seasons, scenarios, climate regimes, and site characteristics

High sensitivity to the climate regime

- All seasons, scenarios, and site characteristics

- Especially in terms of interannual variability

- Increased sensitivity at wetter and lower evaporative demand site

Potential drying impacts increase with larger AWC

- DJ F and MAM only

Potential impacts in DJF and MAM little affected by drainage

Greater sensitivity under native forest than pasture

\section{C atchment water yield}

Direction of change predominantly towards increased water yield

- All seasons, scenarios, climate regimes, and site characteristics

- Little potential for decreased yield

Best guess is increased water yield

- All seasons, scenarios, climate regimes, and site characteristics

Climate regime important in terms of absolute impacts

Scale of impacts sensitive to site characteristics

- Larger absolute but smaller relative potential impacts for pasture

Largest absolute potential increases in J A

Largest relative potential increases in JJ A and SON

Smallest potential increases in DJ F and MAM (but still substantial) water regime is uncertain (reflecting uncertainty about future regional climate change), the finding that the best-guess estimates are for negligible impacts, and the dependence of the potential impacts on the climate regime. Simulation experiments examining the sensitivity of the impact assessment results to site characteristics indicate a range from relatively minor to potentially important. Higher sensitivity associated with the cooler and wetter climate regime, represented by the Pukekohe input data, together with increasing impacts with higher AWC, suggests potentially significant climate change impacts on the soil water regime of the prime agricultural land in the south of the Auckland region.

Two particularly important results emerge from the catchment water yield analysis. First, and in contrast to the soil water regime results, the direction of future climate change impacts is unambiguous. Potential increases in water yield are simulated for all seasons and for all climate change scenarios, whereas potential decreases are nil or minimal in all cases. Second, as with the soil water regime, the water yield analysis results reflect uncertainty about future climate change. So, although it is reasonable to conclude that future climate change may lead to increased surface water resources in the Auckland region, the scale of the impact may range from negligible (even by 2100) to significant (as early as 2020). The scale of any impacts on catchment water yield can be expected to show considerable regional variation, depending on catchment characteristics and the climate regime.

The contrast between the soil water regime and catchment water yield results reported here is striking. The explanation relates to the finite capacity of soil to store water combined with a relatively wet environment. Since there is limited capacity for wet soil to store the additional rainfall simulated for all scenarios, changes in the soil water regime are relatively modest - most of the additional water being routed to runoff, for which no upper limit applies. Also, since actual evaporation is close to the potential rate for much of the year (again due to relatively wet soils), there is limited scope for significant increases in evaporation, other than through elevation of PE. As a consequence of these various factors, runoff increasingly dominates as projected rainfall increases from 2020 to 2100 . This result is likely to be highly sensitive to the climatic regime.

A further particularly curious result of the simulation experiments is the counterintuitive situation where some combinations of $\mathrm{P}$ and $\mathrm{PE}$ change give drier soils but no corresponding decrease in runoff. For example, although Fig. 14 shows potential drying for all seasons and scenarios, Fig. 17 shows a consistent decrease in runoff only for SON. This is due to the fact that the spe- 
cific scenarios producing these situations involve joint increases in both P and PE. What appears to be happening here is that the PE increase, applied every day, is sufficient to reduce mean soil water content by a few $\mathrm{mm}$. The relatively small increase in $\mathrm{P}$ is insufficient to counteract the PE increase, except on and immediately after raindays, but the elevated runoff at these times may partly or completely compensate for reduced runoff associated with the generally drier soils. This counterbalancing effect would be expected to be greatest in J J A when PE is low and soil water contents are high, but is likely to also be highly sensitive to the rainfall intensity characteristics. The result is interesting and warrants further work.

Finally, it is worth emphasising that any assessment of sensitivity is dependent on whether the focus is on absolute or relative impacts. A good example of this is Fig. 17 where much higher relative runoff sensitivity is apparent in the forest environment compared to pasture, although in absolute terms impacts are much higher in the case of pasture. Clearly, any statement about sensitivity needs to be careful defined and be relevant to the specific context. For example, whereas absolute changes may be relevant for a water storage reservoir, relative changes may be more important for water resource applications related to dilution effects.

\section{CONCLUSIONS}

The methodology for climate change scenario development used here enables some of the uncertainties about future climate change to be addressed. The scenario envelopes plotted for the Auckland region in Fig. 7c indicate the sort of results obtained when 4 sources of uncertainty are incorporated. Presentation of the results in this envelope form clearly demonstrates the substantial scale of uncertainty associated with projections of climate change at the regional scale when an attempt is made to deal realistically with the inherent uncertainties.

It is important to recognise that the scenarios presented in Fig. 7c incorporate only a few of many sources of uncertainty. For example, only the Wigley \& Raper (1992) best-guess estimates for the effects of changes in radiative forcing due to sulphate aerosols, stratospheric ozone depletion, and $\mathrm{CO}_{2}$ fertilisation are used. Clearly, the scenario envelopes would be further expanded if uncertainties associated with these elements could also be incorporated. Similarly, it is implicitly assumed that the EI Niño-Southern Oscillation influence on Auckland's climate will remain similar to that experienced in the recent past. It is quite possible that future climate change may be outside the range given in Fig. 7c. Surprises are possible and, given the pace of advancements in the science of scenario development, further significant revision is likely.

From a water resource planning perspective, the uncertainty of regional projections of climate change is one of the most important results of this research. Assessed in terms of the range of plausible climate futures, potential water resource impacts vary substantially in magnitude and even direction. This creates a dilemma for water resource planners: on the one hand, the scale of uncertainty is probably too large to provide a basis for water resource planning decisions; on the other, the scale of potential impacts is too large to ignore.

It is clear that Auckland region water resource planning now, and in the foreseeable future, will face continued significant uncertainty about climate change and its impacts. However, although planning under an uncertain climate is unavoidable, the uncertainty is not open-ended. By identifying the likely 'limits' of potential water resource impacts in the Auckland region, the research presented here provides guidance to planners in terms of possible extremes, best guesses, and the more likely direction of change. For example, the soil water regime results suggest no immediate cause for concern, whereas the catchment water yield results suggest that planners should be aware of possible future increases in supply. More generally, the results suggest no immediate cause for alarm. There is no evidence for substantial decreases in water supply over the next few decades, and even maximum plausible changes to 2020 are unlikely to be critical - potential benefits in terms of increased water resource availability seem more likely. It appears then that regional water resource planners have time to further develop their knowledge of climate change and potential water resource impacts, and to devise appropriate responses.

From an international perspective the work presented here adds to the very limited Southern Hemisphere impacts literature. Results are consistent with the conclusions in the reviews by Lins et al. (1991) and Arnell et al. (1996) regarding the dominating role of precipitation, amplification of changes in climate when transformed into water resource impacts, and the high sensitivity of runoff. One apparent inconsistency is the fact that sensitivity was found to be higher, especially for runoff, for the wetter and cooler Pukekohe site. The change in climate regime is relatively small, compared to that compared by Arnell et al. (1996), where arid and semi-arid sites are concluded to be more sensitive. So the inconsistency may be more apparent than real. It may well be that sensitivity declines from arid through to humid sites, but some threshold may exist after which sensitivity rises again. Alternatively, the direction of sensitivity change may be affected by the 
specific climate regime under investigation. These are important questions which the growing literature on impact studies will help answer.

\section{LITERATURE CITED}

Arnell N, Bates B, Lang H, M agnuson J J , Mulholland P (1996) Hydrology and freshwater ecology. In: Watson RT, Zinyowera MC, M oss RH (eds) Climate change 1995, impacts, adaptations and mitigation of climate change: scientifictechnical analyses. Cambridge University Press, Cambridge, $p$ 325-363

Aston AR (1984) The effect of doubling atmospheric $\mathrm{CO}_{2}$ on streamflow: a simulation.J Hydrol 67:273-280

Aston AR, Dunin FX (1977) An empirical model for drainage from soil under rain-fed conditions. Aust J Soil Res 15: 205-210

Betson RP, Ardis CV J r (1978) Implication for modelling surface water hydrology. In: Betson MJ (ed) Hillslope hydrology. Wiley, Chichester, p 295-323

Black TA (1979) Evapotranspiration from Douglas Fir stands exposed to soil water deficits. Water Resour Res 15: $164-170$

Blake GJ (1975) The interception process. In: Chapman TG, Dunin FX (eds) Prediction in catchment hydrology. Australian A cademy of Science, Canberra, p 59-82

Boorman DB, Sefton CEM (1997) Recognising the uncertainty in the quantification of the effects of climate change on hydrological response. Clim Change 35:415-434

Boughton WC (1986) Linear and curvilinear baseflow recessions. J Hydrol (NZ) 25:41-48

Budyko MI (1980) Klimat v proslom budustem (Climate in the past and in the future). Mysi Publishers, M oscow (in Russian)

Bultot F, Dupriez GL (1985) Daily effective evapotranspiration from a river basin, casebook on operational assessment of areal evaporation. World Meteorological Organization, Geneva

Chiew FHS, Whetton PH, McMahon TA, Pittock AB (1995) Simulation of the impacts of climate change on runoff and soil moisture in Australian catchments. J Hydrol 167: 121-147

Coulter J D (1975) The climate. In: Kushel G (ed) Biogeography and ecology in New Zealand. Junk, The Hague, p 87-138

Cure J D (1985) Carbon dioxide doubling responses: a crop survey. In: Strain BR, Cure JD (eds) Direct effects of increasing carbon dioxide on vegetation. Carbon Dioxide Research Division, United States Department of Energy, Washington, DC, p 99-116

Cure J D, Acock B (1986) Crop responses to carbon dioxide: a literature survey. Agric For M eteorol 38:127-145

de Freitas CR, Fowler AM (1989) Identifying sensitivity to climate at the regional scale: the $\mathrm{New}$ Zealand example. Proc 15th New Zealand Geography Conf, New Zealand Geographical Society Conference Series 15, Wellington, p 254-261

De Lisle J F (1965) The climate of Auckland. Meteorological Office Note 55, New Zealand Meteorological Service, Wellington

Dunin FX, Mclllroy IC, O'Loughlin EM (1985) A Iysimeter characterization of evaporation by eucalypt forest and its representativeness for the local environment. In: Hutchinson BA, Hicks BB (eds) The forest atmosphere interaction. Proceedings of the forest environmental measurements conference, Oak Ridge, Tennessee, 1983. Reidel, Dordrecht, p 271-291

Feddes RA, Kowalik PJ , Zaradny H (1978) Simulation of field water use and crop yield, simulation. Centre for Agricultural Publishing and Documentation, Wageningen

Fowler AM (1992) Climate change and water resources in the Auckland region. PhD thesis, University of Auckland

Fowler AM (1993) Future climate change:coming to terms with the uncertainties. Proc 17th New Zealand Geography Conf, New Zealand Geographical Society Conference Series 17, Wellington, p 95-102

Gifford RM (1988) Direct effects of higher carbon dioxide concentrations on vegetation. In: Pearman GI (ed) Greenhouse: planning for climate change. CSIRO, Melbourne, p 506-519

Gifford RM, Barrett DJ, Lutze J L, Samarakoon AB (1996) Agriculture and global change: scaling direct carbon dioxide impacts and feedbacks through time. In: Walker B, Steffen W (eds) Global change and terrestrial ecosystems. Cambridge University Press, Cambridge, p 229-259

Gordon HB, Whetton PH, Pittock AB, Fowler AM, Haylock MR (1992) Simulated changes in daily rainfall intensity due to the enhanced greenhouse effect: implications for extreme rainfall events. Clim Dyn 8:83-102

Hessell J WD (1988) The climate and weather of the Auckland region. Misc Publ 115(20), New Zealand Meteorological Service, Wellington

Houghton J T, J enkins GJ , Ephraums JJ (eds) (1990) Climate change, the IPCC scientific assessment. Cambridge University Press, Cambridge

Houghton JT, Callander BA, Varney SK (eds) (1992) Climate change 1992: the supplementary report to the IPCC scientific assessment. Cambridge University Press, Cambridge

Houghton JT, Meira Filho LG, Callander BA, Harris N, Kattenberg A, Maskell K (eds) (1996) Climate change 1995: the science of climate change. Cambridge University Press, Cambridge

Hurnard SM (1980) Auckland's climate. Misc Publ 167, New Zealand M eteorological Service, Wellington

Idso SB, Brazel AJ (1984) Rising atmospheric carbon dioxide concentrations may increase streamflow. Nature 312:51-53

J arvis PG, M cNaughton KG (1986) Stomatal control of transpiration:scaling up from leaf to region. Adv Ecol Res 15: 1-49

Kates RW (1985) Preface. In: Kates RW, Ausubel J H, Berberian $M$ (eds) Climate impact assessment: studies of the interaction of climate and society. Wiley, Chichester, $\mathrm{p} x \mathrm{ii}-\mathrm{xix}$

Kimball BA, Idso SB (1983) Increased atmospheric $\mathrm{CO}_{2}$ : effects on crop yield, water use, and climate. Agric Water Manage 7:55-72

Klemes V (1985) Sensitivity of water resource systems to climate variations. World Climate Program Report 98, World M eteorological Organization, Geneva

Klemes $\mathrm{V}$ (1986) Operational testing of hydrological simulation models. Hydrol Sci J 31:13-25

Korner Ch (1996) The response of complex multispecies systems to elevated $\mathrm{CO}_{2}$. In: Walker B, Steffen W (eds) Global change and terrestrial ecosystems. Cambridge University Press, Cambridge, p 20-42

Leavesley GH (1994) M odeling the effects of climate change on water resources - a review. Clim Change 28:159-177

Leggett J , Pepper WJ , Swart RJ (1992) Emission scenarios for IPCC:an update. In: Houghton J T, Callander BA, Varney SK (eds) Climate change 1992: the supplementary report to the IPCC scientific assessment. Cambridge University Press, Cambridge, p 69-96 
Lins HF, Shiklomanov IA, Stakhiv EZ (1991) Impacts on hydrology and water resources. In: J ager J, Ferguson HL (eds) Climate change: science impacts and policy. Proc 2nd World Climate Conference, Cambridge Univ Press, Cambridge, p 87-97

Martin P, Rosenberg NJ , McKenney MS (1989) Sensitivity of evapotranspiration in a wheat field, a forest, and a grassland to changes in climate and direct effects of carbon dioxide. Clim Change 14:117-151

Mather J R (1974) Climatology: fundamentals and applications. McGraw-Hill, New York

McN aughton KG, J arvis PG (1983) Predicting effects of vegetation changes on transpiration and evaporation. In: Kozlowski TT (ed) Water deficits and plant growth, Vol VII: Additional woody plant crops. Academic Press, New York, p 1-47

McNaughton KG, J arvis PG (1991) Effects of scale on stomatal control of transpiration. Agric For Meteorol 54: 279-301

Monteith J L (1965) Evaporation and environment. In: Fogg GE (ed) The state and movement of water in living organisms. Cambridge University Press, Cambridge, p 205-234

M orison J IL (1985) Intercellular $\mathrm{CO}_{2}$ concentration and stomatal response to $\mathrm{CO}_{2}$. In: Zieger E, Farquhar GD, Cowan IR (eds) Stomatal function. Stanford University Press, Stanford, p 229-251

Mullan AB, Renwick JA (1990) Climate change in the New Zealand region inferred from general circulation models. Report prepared for the Ministry for the Environment, Wellington

MWD (1970) Representative basins of New Zealand, 1970. Misc Hydrological Publ No. 7, Water and Soil Division, New Zealand Ministry of Works and Development, Wellington

Nemec J, Schaake J (1982) Sensitivity of water resource systems to climatic variation. Hydrol Sci 27:327-343

NZMS (1983a) Summaries of climatological observations to 1980. New Zealand M eteorological Service M isc Publ 177, Wellington

NZMS (1983b) Temperature normals, 1951 to 1980. New Zealand Meteorological Service Misc Publ 183, Wellington

NZMS (1983c) Rainfall normals for New Zealand, 1951 to 1980. New Zealand M eteorological Service M isc Publ 185, Wellington

NZMS (1986) Summaries of water balance data for New Zealand. New Zealand M eteorological Service Misc Publ 189, Wellington

Pilgrim DH (1986) Bridging the gap between flood research and design practice. Water Resour Res 22:165S-176S

Reid SJ , Penney AC (1982) Upper level wind frequencies and mean speeds for N ew Zealand and Pacific Island stations. New Zealand Meteorological Service Misc Publ 174, Wellington

Roberts J (1983) Forest transpiration: a conservative hydro-

Editorial responsibility: Mike Hulme,

Norwich, United Kingdom logical process. J Hydrol 66:133-141

Rosenberg NJ , M cKenney MS, M artin P (1989) Evapotranspiration in a greenhouse-warmed world: a review and simulation. Agric For M eteorol 47:303-320

RSNZ (1988) Climate change in New Zealand. Misc Series 18, Royal Society of New Zealand, Wellington

Rutter AJ (1968) Water consumption by forests, In: Kozlowski TT (ed) Water deficits and plant growth, Vol II: Plant water consumption and response. Academic Press, New York, p 23-84

Salinger MJ, Hicks DM (1990) The scenarios. In: Climate change impacts on New Zealand: implications for the environment, economy, and society. New Zealand Ministry for the Environment, Wellington, $\mathrm{p}$ 12-18, 238-242

Samarakoon AB, Gifford RM (1995) Soil water content under plants at high $\mathrm{CO}_{2}$ concentration and interactions with the direct $\mathrm{CO}_{2}$ effects: a species comparison. J Biogeogr 22: 193-202

Sangster KB (1986) Throughfall and stemflow in New Zealand kauri (Agathis australis (D. Don) Lindl.). MSc thesis, University of Auckland

Santer BD, Wigley TM L, Schlesinger ME, M itchell J FB (1989) Developing climate scenarios from equilibrium GCM results. Max-Planck-Institut für Meteorologie, Rep 47, Hamburg

Sevruk B (1982) M ethods of correction for systematic error in point precipitation measurement for operational use. Operational Hydrology Report 21, World Meteorological Organization, Geneva

Shuttleworth WJ (1983) Evaporation models in the global water budget. In: Street-Perott A, Beran M, Ratcliffe R (eds) Variations in the global water budget. Reidel, Dordrecht, p 147-171

Shuttleworth WJ, Calder IR (1979) Has the Priestley-Taylor equation any relevance to forest evaporation? J Appl Meteorol 18:639-646

Stewart J B (1977) Evaporation from the wet canopy of a pine forest. Water Resour Res 13:915-921

USDA (1972) SCS national engineering handbook. Soil Conservation Service, United States Department of Agriculture, United States Government Printing Office, Washington, $\mathrm{DC}$

Whetton PH, Fowler AM, Haylock MR, Pittock AB (1993) Implications of climate change due to the enhanced greenhouse effect on floods and droughts in Australia. Clim Change 25:289-317

Wigley TML, J ones PD (1985) Influences of precipitation changes and direct $\mathrm{CO}_{2}$ effects on streamflow. Nature 314: 149-152

Wigley TML, Raper SCB (1992) Implications for climate and sea level of revised IPCC emissions scenarios. Nature 357 : 293-300

Woodward FI (1987) Stomatal numbers are sensitive to increases in $\mathrm{CO}_{2}$ from pre-industrial levels. Nature 327: 617-618

Submitted: April 6, 1998, Accepted: February 8, 1999

Proofs received from author(s): A pril 19, 1999 